\title{
A Three-Dimensional Numerical Study of Deep-Water Formation in the Northwestern Mediterranean Sea
}

\author{
Gurvan Madec, * Michel Chartier, ** Pascale Delecluse* and Michel Crepon* \\ * Laboratoire d'Océanographie Dynamique et de Climatologie, Université Paris 6, Paris, France \\ * *Commissariat à l'Energie Atomique, IPSN/DPS/SEAPS, CEN-FAR, Fontenay-Aux-Roses, France
}

(Manuscript received 14 December 1989, in final form 15 August 1990)

\begin{abstract}
Deep-water formation (DWF) in the northwestern Mediterranean Sea and the subsequent horizontal circulation are investigated in a rectangular basin with a three-dimensional primitive equation model. The basin is forced by constant climatological heat and salt fluxes. Convective motion is parameterized by a simple nonpenetrative convective adjustment process plus Richardson number-dependent vertical eddy viscosity and diffusivity. A homogeneous column of dense water is progressively formed in the forcing area. Meanders of $40-\mathrm{km}$ wavelength develop at the periphery of the column. These features agree with observations. Energy studies show that the meanders are generated mainly through a baroclinic instability process. These meanders, and the associated cells of vertical motion, contribute to the process of DWF. They generate vertical advection, while the associated horizontal advection tends to restratify the surface water of the column, and thus to inhibit very deep convection. Just before the end of the forcing period, $80-\mathrm{km}$ meanders appear, which create advection strong enough to erase the column within two weeks. The associated horizontal cyclonic circulation is of the same order of magnitude as that estimated from observations.
\end{abstract}

\section{Introduction}

Deep-water formation (DWF) in the open sea occurs in very few regions of the world ocean. Such regions are mainly found in subpolar areas of both hemispheres: the Greenland Sea (Carmack and Aagaard 1973), the Labrador Sea (Clarke and Gascard 1983; Gascard and Clarke 1983), and the center of the Weddell Sea (Gordon 1978). But DWF also occurs in concentration basins at lower latitudes, namely, the Red Sea (Maillard 1974) and the northwestern Mediterranean (NWM) Sea (MEDOC Group 1970). The study of these regions and of the mechanisms responsible for DWF is very important for understanding the rate of renewal of the different deep-water masses of the global ocean. The mechanisms driving DWF have been found to be similar from one region to another (Lacombe 1974; Gascard 1977; Killworth 1983). They are always associated with a mesoscale cyclonic circulation, with the existence of a source of both salt and heat from subsurface layers, and with intense surface cooling and evaporation. The NWM Sea has been extensively observed during the MEDOC cruises of 1969 , 1970,1972 , and 1975, and more recently by Schott et al. (1988). It is a midlatitude basin formed of a three-

Corresponding author address: Dr. Gurvan Madec, Laboratoire d'Oceanographie Dynamique et de Climatologie, Universite Paris 6, 75005 Paris, France. layer system of fresh surface water originating from the Atlantic Ocean, of warm and salty subsurface water derived from the eastern Mediterranean Sea (Levantine Intermediate Water), and of Western Mediterranean Deep Water (Nielsen 1912). The basin is characterized throughout the year by a doming of isopycnal surfaces (Tchernia and Fieux 1971), the center of which is usually found about $100 \mathrm{~km}$ south of the French coast (Fig. 1). Surface and subsurface water masses flow cyclonically around this dome. This circulation is well marked in its northern part where it forms the so-called Liguro-Provencal Current (Millot 1987). In winter the NWM Sea is forced by a succession of strong, cold, and dry continental wind events. These winds (the mistral and the tramontane) blow from the north-northwest down the Rhône and Garonne river valleys and out over the central part of the NWM Sea. They are responsible for high evaporation and strong cooling in this area.

Through a variety of studies (Anati and Stommel 1970; MEDOC Group 1970; Stommel 1972; Sankey 1973; Lacombe 1974; Killworth 1976; Gascard 1977; 1978; Killworth 1983), a conceptual framework of DWF in the NWM Sea has emerged that divides the process into three phases: a preconditioning phase, a violent mixing phase, and a sinking and spreading phase.

The preconditioning phase consists in the generation of a cyclonic vortex inscribed in the regional cyclonic circulation (Fig. 1), where the main thermocline is 


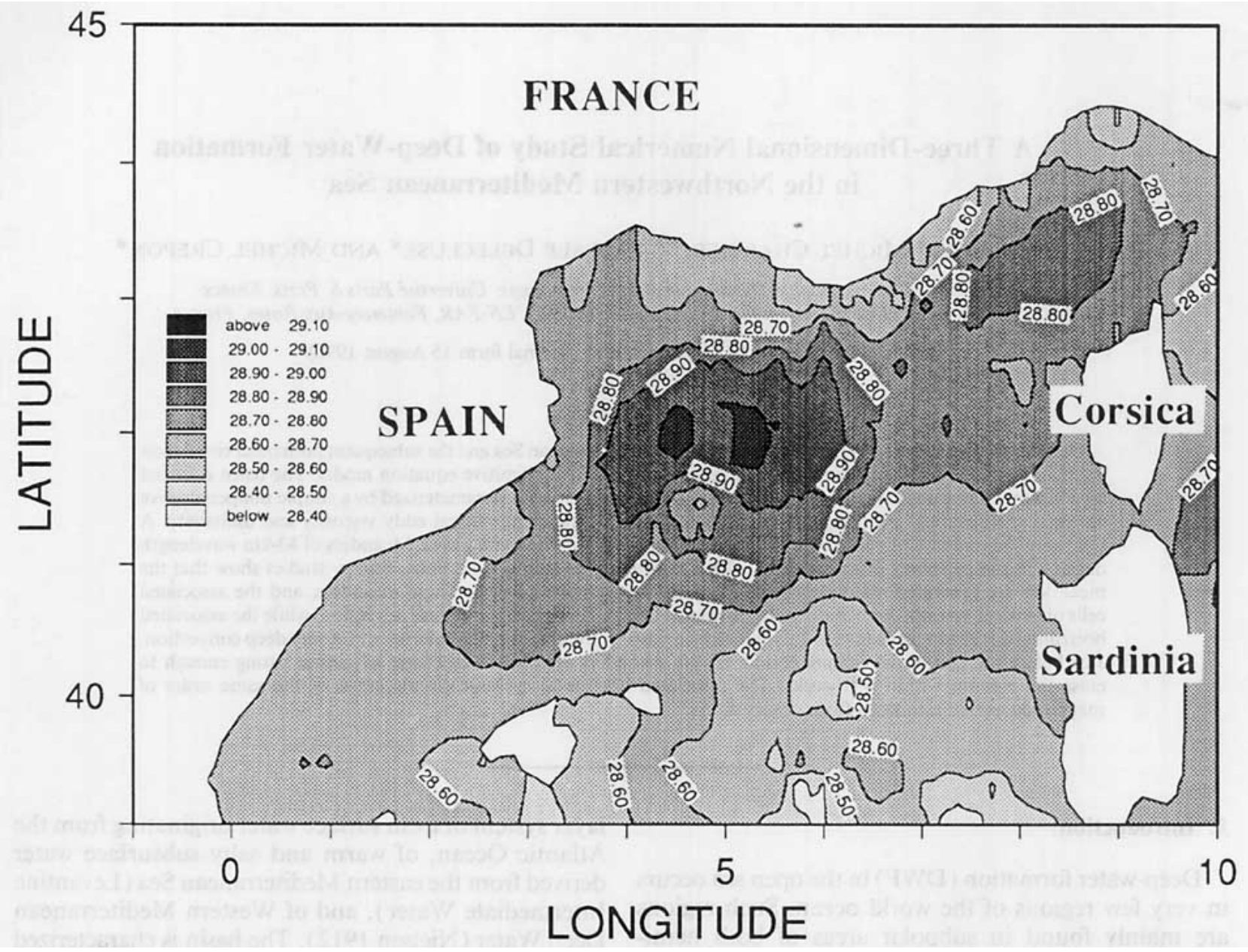

FIG. 1. Sea surface density ( $\sigma_{\theta}$ units) in winter obtained from an objective analysis of winter historical data (from 1905 to 1988) (F. Aikman III, personal communication). The 28.90 isopycnal defines the cyclonic vortex area where DWF occurs.

progressively eroded. This vortex, $\sim 100 \mathrm{~km}$ in diameter, defines the specific area for DWF (Gascard 1978). Two mechanisms have been advanced to account for the vortex formation. Swallow and Caston (1973) and Hogg (1973) suggest the cause of the vortex is the conelike topography of the Rhône fan. Sankey (1973) and Gascard (1978) ascribe the preconditioning to both the localization of the atmospheric forcing and the preexisting regional cyclonic circulation: a vortex is formed in the central part of the domed region because these waters, trapped by the cyclonic circulation, are exposed for a longer time to atmospheric effects than the peripheral waters, and because the surface waters are less stratified in the center than at the periphery of the dome.

As winter progresses, surface waters trapped by the vortex lose heat and water vapor to the atmosphere. They become more dense and mix with the warmer, saltier subsurface waters. The presence of this subsurface source of heat and salt is thought to be important (Gascard 1978), as it allows the surface temperature and salinity to remain relatively high, which in turn contributes to the maintenance of high heat and water vapor exchanges with the atmosphere in the convective region. The convection can penetrate quite deep. A neutrally stable column of water is formed in the vortex center. It extends from the surface to depths that steadily increase, sometimes to the ocean bottom (the local depth is $\sim 2400 \mathrm{~m}$ ). This phase of intense deepening of the column is called the violent mixing phase since it is associated with strong vertical motions. The mechanism of this phase is generally explained by two kinds of processes that occur alternatively or together: 1) a convective process and 2) a baroclinic adjustment process (Gascard 1978).

1) The convective process has small time and space scales $(\sim 1$ hour, $\sim 1 \mathrm{~km})$ and is associated with intense vertical velocities, from a few centimeters per second (Voorhis and Webb 1970) up to $10-20 \mathrm{~cm} \mathrm{~s}^{-1}$ when the stratification within the vortex becomes very weak (Gascard 1978; Schott et al. 1988). It involves nonhydrostatic and nonlinear motion, such as breaking of 
large-amplitude internal waves (Saint-Guily 1972; Gascard 1973).

2) The baroclinic adjustment process is the result of slow upward and downward motion (a few $\mathrm{mm} \mathrm{s}^{-1}$ ) that occurs in cyclonic and anticyclonic eddies of $\sim 10$ $\mathrm{km}$ in diameter and with $\sim 3$ days rotational period. These eddies are associated with $40-\mathrm{km}$ wavelength meanders that develop at the edge of the vortex (Gascard 1978). These meanders are thought to be produced through baroclinic instability process (Killworth 1976; Gascard 1977, 1978).

The final phase of the process is a breakup, or sinking and spreading of the neutrally stable column of water, with a rapid restratification of the surface waters, which can occur within two weeks (Stommel 1972). This phase involves larger eddies than those formed previously ( $\sim 20 \mathrm{~km}$ in diameter) with surface velocities of about $15 \mathrm{~cm} \mathrm{~s}^{-1}$ (Sankey 1973). Killworth (1976) also attributes this phase to baroclinic instability processes.

During the remainder of the year, the newly formed deep water moves away from the formation region. The surface and intermediate waters are replaced by waters advected by the Liguro-Provencal Current, while the atmosphere resumes the seasonal heating of the ocean in the surface layers. The three-layer stratification is reestablished and the regional cyclonic circulation continues (Millot 1987).

Deep water thus results from an interaction between oceanic circulation and atmospheric forcing. Its formation involves complex and intricate phenomena that operate over a large range of time and space scales, and which can include deep convection, mixing processes, internal waves, baroclinic instabilities, topographic effects, and wind- and thermohaline-driven currents. Even though a scheme of DWF has been presented, many theoretical problems still exist. Very little is known about the horizontal circulation induced by convection and subsequent DWF. In the case of the NWM Sea, the Liguro-Provencal Current cannot be explained either by the fluxes through the straits of Gibraltar and Sicily (Loth and Crépon 1984), nor by the action of the wind stress (Heburn 1987). Crépon and Boukthir (1987), Crépon et al. (1989), and Barnier et al. (1989) addressed this problem using first an analytical and then a quasi-geostrophic numerical approach. They have shown that the Liguro-Provencal Current could be partly generated by thermohaline forcing and subsequent DWF. Seung (1987) also found that thermohaline forcing driven by regional variations in the air-sea fluxes is a likely driving mechanism for the development of the large cyclonic gyre observed by Clarke and Gascard (1983) in the Labrador Sea.

In this paper, we investigate DWF in the NWM Sea and its associated circulation using a three-dimensional primitive equation model where temperature and salinity are explicitly taken into account. We focus our attention on the general circulation induced by the change in surface density, on the occurrence of meanders, and on their space, time, and energetic characteristics. Small-scale processes would need very fine horizontal resolution (some hundred meters) and inclusion of new physics such as the relaxation of the hydrostatic assumption. These are not studied here, but simply parameterized via a nonpenetrative convective adjustment algorithm and by vertical eddy diffusivity and viscosity coefficients, which are a function of the local Richardson number. We focus our study on the violent mixing and ensuing sinking and spreading phases of DWF. We are not trying to simulate the development of the vortex in detail from observed atmospheric fields (i.e., the preconditioning phase). However, by applying the thermohaline forcing over an oval area, we expect to create a cyclonic vortex of the correct size and structure in order to investigate the development of the further phases of DWF.

After a brief presentation of the model in section 2 , we investigate in section 3 the effects of an idealized thermohaline forcing. We demonstrate that the model is able to reproduce the main features of DWF and we study the associated horizontal circulation. The energetics involved in instability phenomena that occur during the DWF are further studied in section 4, where the response of the ocean to a thermohaline forcing is investigated in a periodic channel. Finally, in section 5 , we discuss the numerical results and their signifcance.

\section{Model description}

This study has been performed with the multilevel numerical model developed at the Laboratoire d'Oceanographie Dynamique et de Climatologie (LODYC) under the direction of P. Delecluse (Chartier 1985; Andrich et al. 1988). The model solves the primitive equations, i.e., the three-dimensional NavierStokes equations slightly simplified by assuming the Boussinesq approximation, hydrostatic equilibrium, and the rigid-lid approximation (Bryan 1969). The equations are solved on an Arakawa type " $C$ " grid (Arakawa 1972) with a curvilinear formulation in the three space directions. Time stepping is achieved by a leapfrog scheme, with the spurious time splitting being removed by an Asselin (1972) time filter. The potential enstrophy-conserving finite difference formulation given by Sadourny (1975) is fitted to the nonlinear terms of the momentum equation. This property is further addressed in the Appendix, where enstrophyconserving and energy-conserving simulations are compared. The finite differencing scheme for the advection terms conserve salt and heat contents. The prognostic variables are the horizontal velocity $\mathbf{U}_{h}$ $=(u, v)$, the temperature $T$, and the salinity $S$. The vertical velocity $w$, the density $\rho$, and the hydrostatic pressure $p$ are diagnostic variables computed at each time step from the prognostic variables using the con- 
tinuity, state, and hydrostatic equations, respectively. The vertically averaged current and the deviation from the mean are calculated separately at each time step. The former is computed by a preconditioned conjugate gradient algorithm (Madec et al. 1988), and the latter by integrating the horizontal momentum equation in time while removing the barotropic components. Acting this way, the surface pressure is not explicitly calculated and we only consider the hydrostatic part of the pressure term in the momentum equations. The model runs on a CRAY2 in a multitasked version. A detailed description of the model and its numerical performances are given in Andrich (1988) and Andrich et al. (1988).

Let $\mathbf{k}$ be the unit upward vertical vector. The momentum equations on a rotating sphere are

$$
\begin{gathered}
\partial_{t} \mathbf{U}_{h}+\left(\operatorname{rot}_{z} \mathbf{U}_{h}+f\right) \mathbf{k} \times \mathbf{U}_{h}+w \partial_{z} \mathbf{U}_{h} \\
=-\frac{1}{\rho_{0}} \operatorname{grad}\left(p+\frac{1}{2} \rho_{0} \mathbf{U}_{h}{ }^{2}\right)+F^{U}(\mathbf{U}) \\
\partial_{z} p=-\rho g .
\end{gathered}
$$

The continuity equation leads to

$$
\operatorname{div} \mathbf{U}_{h}+\partial_{z} w=0 .
$$

The temperature and salinity conservation equations are

$$
\begin{aligned}
& \partial_{t} T+\operatorname{div}\left(T \mathbf{U}_{h}\right)+\partial_{z}(T w)=F^{T}(T) \\
& \partial_{t} S+\operatorname{div}\left(S \mathbf{U}_{h}\right)+\partial_{z}(S w)=F^{S}(S) .
\end{aligned}
$$

Here $F^{U}, F^{T}$, and $F^{S}$ parameterize the effects of subgrid-scale physics, i.e., eddy viscosity and eddy diffusivity. They are assumed to be second-order operators of the following form:

$$
\begin{aligned}
F^{U}(\mathbf{U})= & \nu_{h}\left[\operatorname{grad}_{h}\left(\operatorname{div} \mathbf{U}_{h}\right)-\operatorname{rot}\left(\operatorname{rot} \mathbf{U}_{h}\right)\right] \\
& +\partial_{z}\left(\nu_{v} \partial_{z} \mathbf{U}_{h}\right) \\
F^{T}(T)= & \kappa_{h T} \operatorname{div}\left(\operatorname{grad}_{h} T\right)+\partial_{z}\left(\kappa_{v} \partial_{z} T\right) \\
F^{S}(S)= & \kappa_{h S} \operatorname{div}\left(\operatorname{grad}_{h} S\right)+\partial_{z}\left(\kappa_{v S} \partial_{z} S\right) .
\end{aligned}
$$

The density is calculated by a simplified nonlinear equation of state (Eckart 1958).

The numerical integration may lead to static instabilities at particular grid points. In the ocean, convective processes reestablish the static stability. These processes have been removed from the model via the hydrostatic assumption: they must be parameterized. This is done by a nonpenetrative convective adjustment algorithm, which restores instantaneously and at each time step the static stability by mixing downward the statically unstable portion of the water column, but only until the density structure becomes neutrally stable (i.e., until the mixed portion of the water column has exactly the density of the water just below). Such a nonpenetrative convective algorithm is consistent with winter observations in the MEDOC area (Anati 1971; Killworth 1976). This algorithm is an iterative process used in the following way: going from the top of the ocean toward the bottom, the first instability is searched. Assume in the following that the instability is located between levels $k$ and $k+1$. The two levels are vertically mixed, for temperature and salinity, conserving the heat and salt contents of the water column. The density is then computed. It is not exactly conserved, since the equation of state is nonlinear. If the new profile is still unstable under level $k+1$, levels $k$, $k+1$, and $k+2$ are then mixed. This process is repeated until stability is established (the mixing process can go down to the ocean bottom). The algorithm is repeated to check that there is no deeper instability. It is worth noting that the algorithm converges for any profile in a number of iterations less than the number of vertical levels of the model.

The surface boundary conditions are

$$
\begin{aligned}
w & =0 \\
\nu_{v} \partial_{z} U_{h} & =0 \\
\kappa_{v T} \partial_{z} T & =\frac{Q}{\rho_{0} C_{p}} \\
\kappa_{v S} \partial_{z} S & =\frac{S E}{C_{S}}
\end{aligned}
$$

where $Q$ is the surface heat flux (latent and sensible heat flux and net radiative flux) (in $\mathrm{W} \mathrm{m} \mathrm{m}^{-2}$ ), $E$ is the surface water flux (evaporation minus precipitation) (in $\mathrm{mm} \mathrm{d}^{-1}$ ), and where $C_{p}=4 \times 10^{3} \mathrm{~J} \mathrm{~kg}^{-1}{ }^{\circ} \mathrm{C}^{-1}$ and $C_{S}=864 \times 10^{5} \mathrm{~mm} \mathrm{~d}^{-1}$ are physical constants.

"No-slip" boundary conditions are assumed at lateral walls and bottom friction is not considered. Zero fluxes of heat and salt are applied at the solid boundaries.

For all the numerical experiments performed in this study, the ocean starts from rest with a horizontally homogeneous density field computed from temperature and salinity profiles given in Fig. 2. Vertical temperature and salinity gradients are typical of the NWM Sea in early winter. The cold and relatively fresh surface water with a subsurface temperature minimum at 100 $m$ overlies the warm and salty Levantine Intermediate Water (LIW) between 200 and $600 \mathrm{~m}$, and a typical thick layer of deep water (Nielsen 1912). The complexity of the vertical profiles of both temperature and salinity leads us to refine the mesh with up to 20 vertical levels, whose separation varies from 10 to $25 \mathrm{~m}$ in the upper $200 \mathrm{~m}$ and is no more than $400 \mathrm{~m}$ at the bottom (Fig. 2). Such an initial stratification presents very small baroclinic radii of deformation (Table 1). A 4.5$\mathrm{km}$ horizontal grid spacing has therefore been chosen for all the experiments. Such grid spacing resolves the first baroclinic mode and thus ensures the quality of the numerical schemes associated with the $\mathrm{C}$ grid (Bat- 


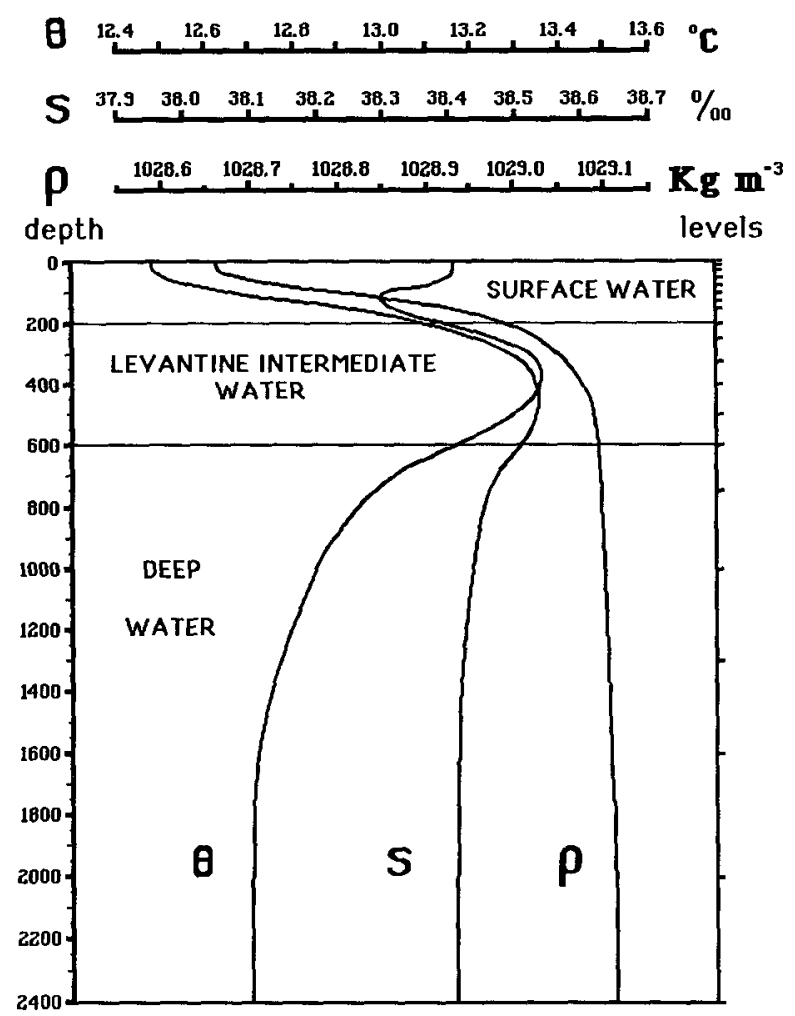

FIG. 2. Initial vertical structure for potential temperature, salinity, and potential density ( $\sigma_{\theta}$ units) versus depth (on the left). The depth of the model vertical levels are indicated on the right of the frame.

teen and Han 1981; Hsieh et al. 1983; Wajsowicz 1986). The time step is $30 \mathrm{~min}$. A $80 \mathrm{~m}^{2} \mathrm{~s}^{-1}$ horizontal eddy mixing coefficient is assumed for momentum, salinity, and temperature. This small value, corresponding to the $4.5-\mathrm{km}$ grid, prevents computational instabilities. The model sensitivity to this parameter will be addressed in section 4 . Vertical eddy viscosity and eddy diffusivity coefficients are assumed to vary as a function of the local Richardson number $\mathrm{Ri}$, according to the parameterization of Pacanowski and Philander (1981). They vary from the temperature molecular diffusivity $\left(1.34 \times 10^{-2} \mathrm{~cm}^{2} \mathrm{~s}^{-1}\right)$ to a maximum value of $10^{2} \mathrm{~cm}^{2} \mathrm{~s}^{-1}$ when $\mathrm{Ri}$ is zero.

The above governing equations are solved in two basins of different geometries, which are used for the two numerical experiments performed in this study. In experiment $\mathrm{I}$, the model basin is a closed, flat rectangular basin of $500 \mathrm{~km} \times 250 \mathrm{~km} \times 2.4 \mathrm{~km}$ centered

TABLE 1. First three internal radii of deformation $R_{n}$ for the initial stratification and their corresponding wavelengths $\lambda_{n}$.

\begin{tabular}{ccc}
$\begin{array}{c}\text { Mode } \\
(n=)\end{array}$ & $\begin{array}{c}R_{n} \\
(\mathrm{~km})\end{array}$ & $\begin{array}{c}\lambda_{n}=2 \pi R_{n} \\
(\mathrm{~km})\end{array}$ \\
\hline 1 & 6.53 & 41.0 \\
2 & 3.00 & 20.0 \\
3 & 2.00 & 12.0 \\
\hline
\end{tabular}

at $42^{\circ} \mathrm{N}$, which accounts for the so-called MEDOC area. The thermohaline forcing, shown in Fig. 3b, is applied over an oval area $(200 \mathrm{~km} \times 100 \mathrm{~km})$, which approximately fits the observed vortex pattern. Its maximum corresponds to the center of the area and is situated $100 \mathrm{~km}$ off the northern coast. This thermohaline forcing is assumed to be constant during the first four months of integration and zero thereafter with a rise and fall time of 10 days (Fig. 3a). It consists of an ocean heat loss of $170 \mathrm{~W} \mathrm{~m}^{-2}$ and an evaporation of 6.3 millimeters of water per day. These are the mean winter values deduced from the monthly mean estimations given by Bunker (1972) for the MEDOC area.

In experiment II, the model basin is a flat zonal periodic channel of $320 \mathrm{~km} \times 150 \mathrm{~km} \times 2.4 \mathrm{~km}$ centered at $42^{\circ} \mathrm{N}$. A thermohaline forcing is applied in the southern part of the channel. It has the same charac-
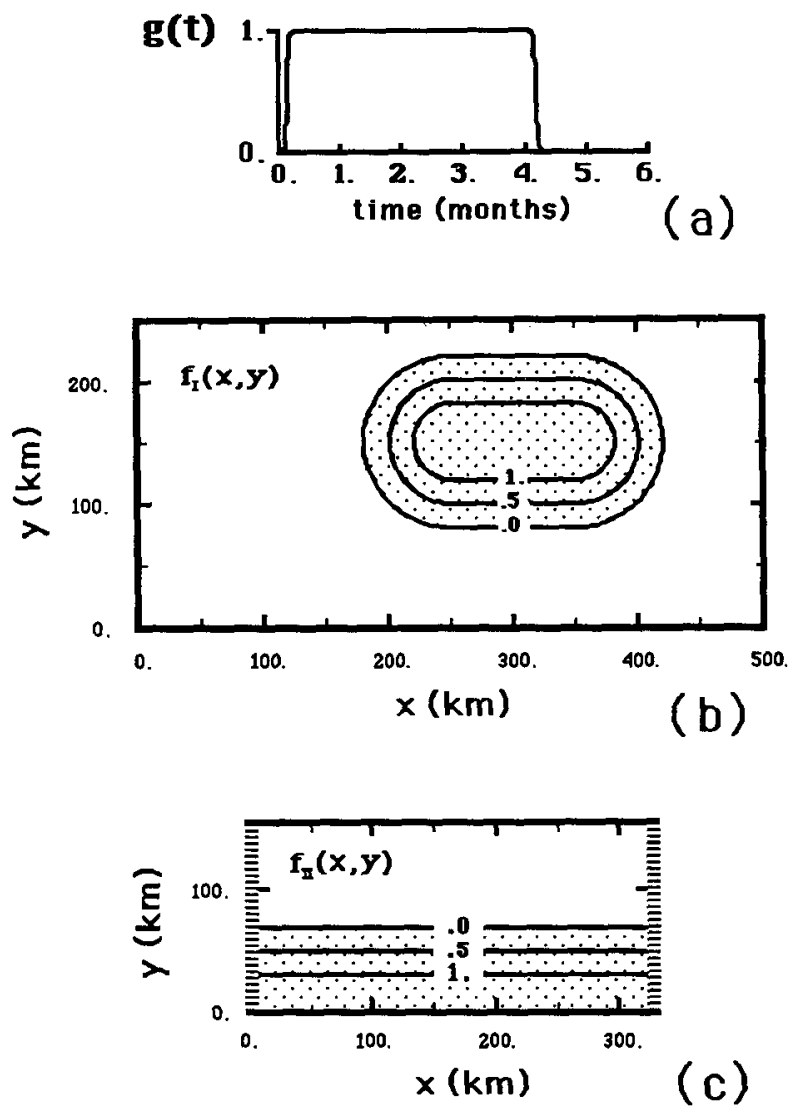

FIG. 3. Basin geometry and time and space characteristics of the thermohaline forcing: (a) time evolution of the forcing function $g(t)$ for both experiments; (b) shape of the thermohaline forcing $f_{1}(x, y)$ for experiment I. The total heat flux $Q$ and the evaporation $E$ are given by $Q=Q_{0} g(t) f_{1}(x, y)$ and $E=E_{0} g(t) f_{1}(x, y)$; (c) shape of the thermohaline forcing $f_{\mathrm{II}}(x, y)$ for experiment II. Terms $Q$ and $E$ are then given by $Q=Q_{0} g(t) f_{\mathrm{H}}(x, y)(1+\alpha R(x, t))$ and $E$ $=E_{0} g(t) f_{\mathrm{II}}(x, y)(1+\alpha R(x, t))$, where $R$ is a random function, which has a white spectrum in both $x$ and $t$ and ranges between -1 and +1 . The amplitude of the random noise is $\alpha=0.1$. In both cases, $Q_{0}$ and $E_{0}$ have the same mean winter values: $Q_{0}=-170 \mathrm{~W} \mathrm{~m}^{-2}$ and $E_{0}=6.3 \mathrm{~mm} \mathrm{~d}^{-1}$ 
teristics in terms of magnitude, horizontal gradient, and time variation as in experiment $\mathrm{I}$, but a random noise with a white spectrum in zonal direction and time has been added to this forcing (Fig. 3c). This random noise is required to provide a rapid generation of the instabilities. Without such a random forcing, the response of the ocean in this experiment stays purely zonal throughout the forcing period. Note that for this experiment, the boundary conditions defined previously are not sufficient to determine the net volumetric transport across the channel, because of the east-west periodic conditions. This indeterminancy is a consequence of the rigid-lid assumption. It is removed by employing a line integral of the vertically averaged momentum equations along the north channel wall. This is a standard practice in many circulation models. We followed the methodology given by Jensen (1986).

\section{Experiment I: Response to the oval-shape ther- mohaline forcing}

The thermohaline forcing generates thermodynamic and dynamic responses in the ocean: it induces changes in the temperature and salinity in the forcing area, which create horizontal density gradients and therefore generate a circulation. This circulation induces horizontal advection of water masses, which eventually influences the evolution of the $T-S$ characteristics of the seawater. Although these effects are strongly linked, it is convenient to present them separately.

\section{a. Thermodynamic response}

As long as the thermohaline forcing is active, surface water within the forcing area becomes denser. Convective adjustment occurs that causes surface water to mix with subsurface water. A neutrally stable column of water is formed in the forcing area. The time evolution of the column depends on three factors: the thermohaline forcing, which increases the surface density and thus induces convection; the vertical stratification beneath the column, which controls the deepening rate; and the horizontal dynamics, which can change the characteristics of the waters involved in the convection. In order to investigate the relative effects of the convection with respect to the horizontal dynamics, we run the model in a vertical one-dimensional version, which describes the time evolution of the column depending only on the convective adjustment algorithm during a 4-month period of thermohaline forcing.

Consider first the behavior of the one-dimensional model (Fig. 4, curve $i$ ). Because the thermohaline forcing is constant throughout the 4-month period, it can be shown that the time derivatives of the depth $H$ and the density $\rho_{c}$ of the neutrally stable column approximately fit the following relations:
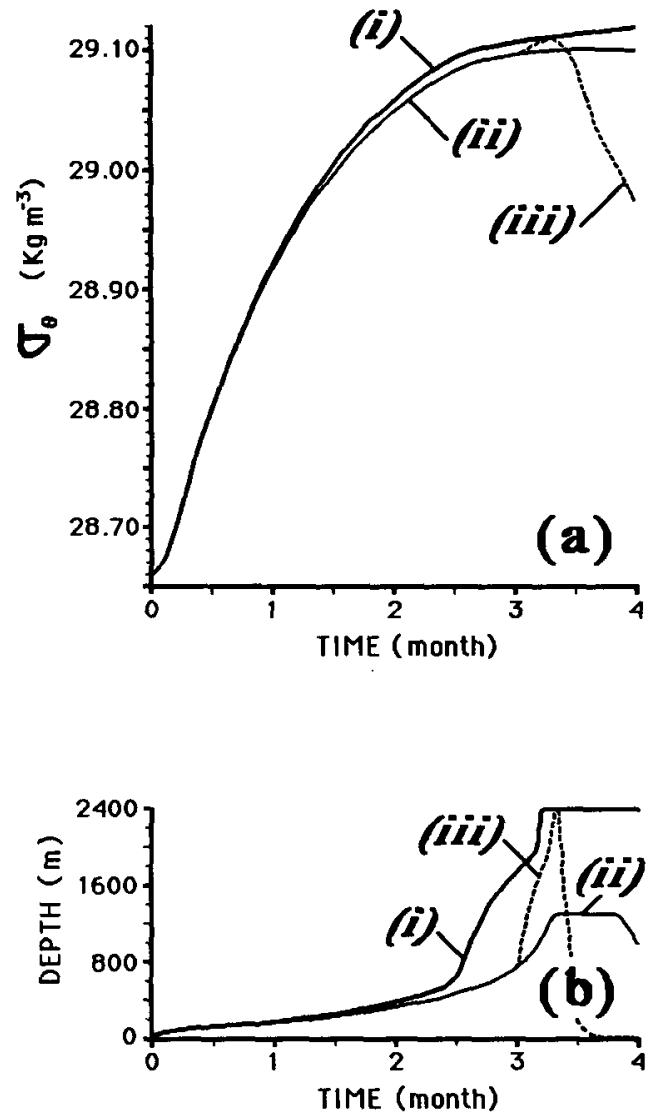

FIG. 4. Time evolution of the characteristics of the neutrally stable water column: (a) potential density ( $\sigma_{\theta}$ units) and (b) depth, for: ( $i$ ) the vertical one-dimensional model with four months of constant thermohaline forcing; ( $i i)$ experiment I with the basic forcing; and (iii) experiment I, except for the fourth month, when the thermohaline forcing is concentrated in the first 10 days (i.e., $Q=-510 \mathrm{~W} \mathrm{~m}^{-2}$ and $E=18.9 \mathrm{~mm} \mathrm{~d}^{-1}$ ) only.

$$
\begin{aligned}
& \frac{d H}{d t} \propto\left(\partial_{z} \rho_{u} t\right)^{-1 / 2} \\
& \frac{d \rho_{c}}{\mathrm{dt}} \propto\left(\frac{\partial_{z} \rho_{u}}{t}\right)^{1 / 2}
\end{aligned}
$$

where $\partial_{z} \rho_{u}$ is the vertical density gradient of the water just under the column. Initially, the convection involves the well-stratified surface waters. Following (7), the column deepening rate is slow $\left(\sim 4 \mathrm{~m} \mathrm{~d}^{-1}\right)$ and its density increase rate is relatively fast (Fig. $4 a$ ). When all the surface waters have been homogenized (i.e., at $\sim 2$ months), the convection involves less stratified waters. The column density increase rate slightly weakens while its deepening rate strongly increases from $\sim 10 \mathrm{~m} \mathrm{~d}^{-1}$ at 2 months to more than $90 \mathrm{~m} \mathrm{~d}^{-1}$ after 3 months (Fig. 4b). The column reaches the bottom of the ocean at 3.2 months. Then, its density continues to increase, but at a constant rate that depends only on the ratio between the ocean depth and the removal of buoyancy induced by the forcing. 
The column behavior is significantly different in the case of the three-dimensional model (Fig. 4, curve $i i$ ). During the first 2 months, both depth and density of the column have nearly the same behavior for each model, i.e., horizontal dynamics is negligible and the process is mainly vertical. By 2 months, the column is slightly lighter than in the one-dimensional case. Since the stratification of deep waters is very weak, a small vertical density difference leads to a strong depth change (up to $1000 \mathrm{~m}$ at 3.3 months) when the deep waters are involved in the convective process (i.e., after 2.5 months). This density difference mainly originates from horizontal advection, which is linked to meanders that develop around the column after the second month (see section $3 \mathrm{~b}$ ). They tend to bring less dense fluid to the surface layers of the column, where it becomes involved in the convective process and the resulting water mass is lighter. Between 3.3 and 3.8 months, a balance occurs between the lightening of surface water induced by advection and the increase of density induced by the thermohaline forcing. Both the depth and density of the column then remain constant. By 3.8 months, meander activity becomes large enough to destroy the balance in favor of the advective effects. Both the density and depth of the column decrease until the fourth month.

The existence of a balance between advective effects and the density increase is artificial. It results from the assumption of a constant value for the winter thermohaline forcing. In the real ocean, the thermohaline forcing is strongly time dependent due to the occurrence of wind events, which act for some days and can induce heat losses that reach $700 \mathrm{~W} \mathrm{~m}^{-2}$ and evaporation greater than $2 \mathrm{~cm} \mathrm{~d}^{-1}$. During such events, the density increase due to the forcing strongly dominates the effects of advection, while advective effects predominate between these events. The convective depth depends a great deal on such time variation of the forcing. We have run the model as in experiment I, except for the fourth month, where the thermohaline forcing was increased by a factor of 3 in the first 10 days of this month and set to zero thereafter (see Fig. 4, curve iii). The horizontal advection is not strong enough to balance the forcing during the first 10 days. The neutrally stable column becomes more dense and convection reaches the bottom at 3.3 months. At this time, the forcing stops and horizontal advection rapidly restratifies the surface water, so that both depth and density of the column decrease.

The time evolution of the $T-S$ characteristics of the column for experiment $I$ is shown in Fig. 5. From month 0 to 1.8 , only the fresh and relatively cold surface water $(0-200 \mathrm{~m})$ is involved in the convection. The column salinity slowly increases to reach 38.25 psu, while its temperature diminishes to reach a minimum of $12.3^{\circ} \mathrm{C}$ at month 1.8 . The LIW $(200-800 \mathrm{~m})$ then becomes involved in the convection. Since LIW is a source of both salt and heat, the column salinity
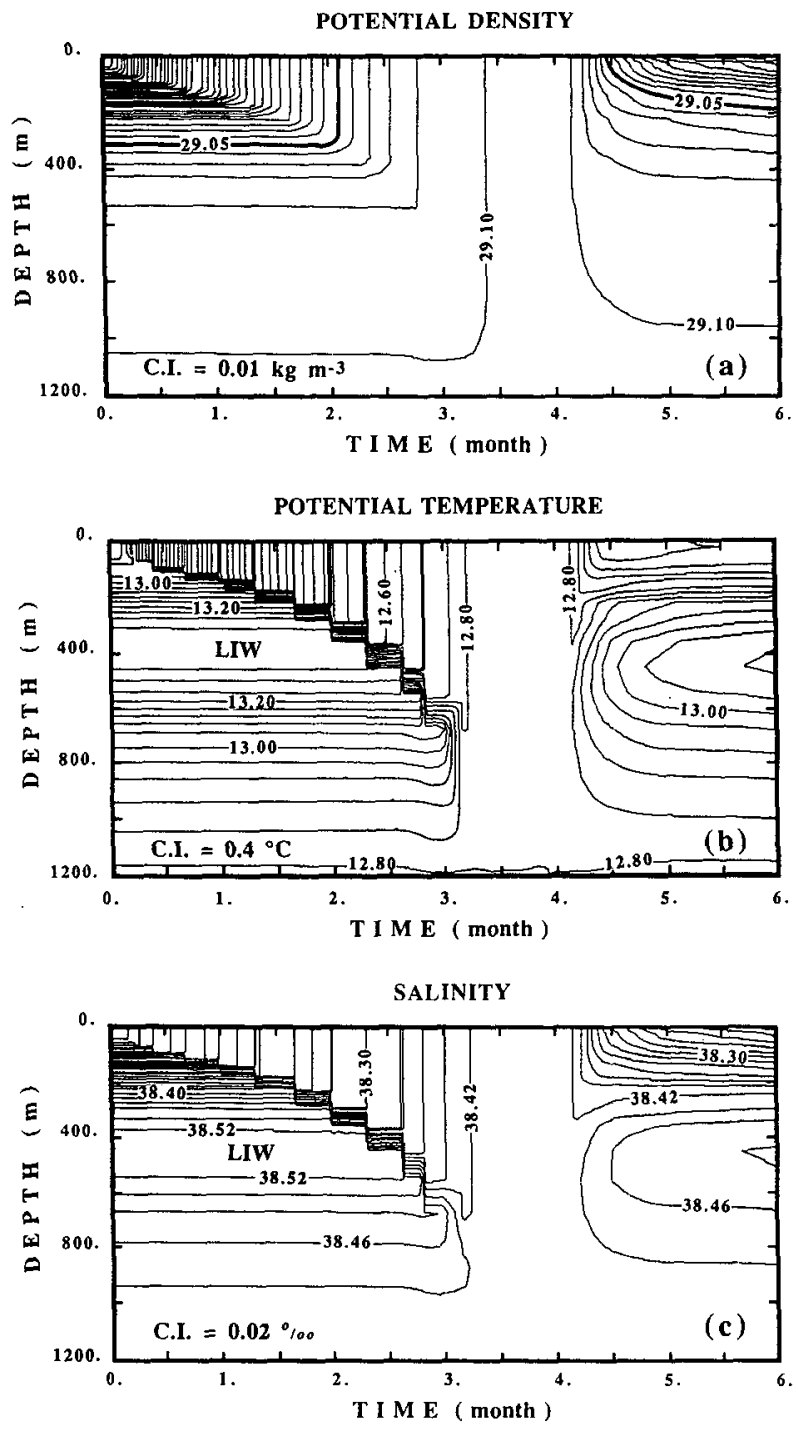

FIG. 5. Time evolution of the vertical structure of the top $1200 \mathrm{~m}$ in the center of the forcing area $(x=300 \mathrm{~km} ; y=150 \mathrm{~km})$ : (a) potential density ( $\sigma_{\theta}$ units), (b) potential temperature, and (c) salinity. The contour intervals $(\mathrm{CI})$ are as indicated.

continues to increase, but at a higher rate, while its temperature now increases. After three months, all the LIW within the forcing area has been mixed. The salinity reaches $38.4 \mathrm{psu}$ and the temperature exceeds $12.8^{\circ} \mathrm{C}$ (Fig. 5). Sea-surface heat and salt fluxes are then balanced by the advection of relatively warm and fresh surface water. The $T-S$ characteristics of the column remain nearly constant during the fourth month. By the end of the forcing period, the column is about $1300 \mathrm{~m}$ deep and its $T-S$ characteristics $\left(T=12.8^{\circ} \mathrm{C}\right.$, $S=38.42 \mathrm{psu})$ are close to those of the deep water ( $T$ $\left.=12.7^{\circ} \mathrm{C}, S=38.41 \mathrm{psu}\right)$. Two weeks after the end of the forcing period, a restratification of surface and subsurface waters $(0-800 \mathrm{~m})$ has occurred caused by the advection of lighter peripheral water masses. 
Note that the density profiles (Fig. 5a) do not show discontinuity as is expected from the nonpenetrative convective adjustment algorithm used. On the contrary, a strong discontinuity in both temperature and salinity profiles (Figs. 5b,c) indicates the bottom of the neutrally stable column. This is due to the rather different $T-S$ characteristics of water masses within and below the column. The time evolution of this discontinuity exhibits steplike features, which are determined by the discrete vertical representation of the model.

At 3.3 months, a vertical section given by the numerical model (Fig. 6) is consistent with observations (Fig. 7) obtained during the MEDOC 69 cruise at the beginning of February (Tchernia and Fieux 1971). For both measurements and model results, the neutrally stable column has nearly the same $T-S$ characteristics. Surface waters present a relative temperature and salinity maximum in the center of the column. This surface signature of the deep convective area is useful since it helps to identify the deep convective area just by using a shipboard thermosalinograph (Schott et al. 1988). In both the observations and the simulation, a surface-temperature minimum is found at the outer edge of the column where convection induced by the forcing is not strong enough to involve the source of heat that constitutes the LIW.

\section{b. Dynamic response}

During the first 2 months, the response of the ocean to the thermohaline forcing fits the linear theory de- veloped by Crépon and Boukthir (1987) and Crépon et al. (1989). Surrounding the neutrally stable column, a horizontal density gradient appears (Fig. 8a) that drives horizontal baroclinic currents in geostrophic balance. A cyclonic gyre is formed in the upper layers whose horizontal pattern is similar to the forcing geometry. Its mean velocity is $10 \mathrm{~cm} \mathrm{~s}^{-1}$. A weaker countercurrent appears in the deep layers, which forms an anticyclonic gyre whose horizontal velocity is quasiuniform with respect to the vertical: a few millimeters per second.

After this 2-month period, meanders begin to develop along the front that defines the neutrally stable column (Fig. 8). By month 3 (Fig. 8c), 12 meanders have developed with a wavelength $\lambda$ of $\sim 40 \mathrm{~km}$, which corresponds to a first baroclinic mode oscillation (Table 1). Such meanders have been observed in early winter satellite pictures (Crépon et al. 1982) and during the violent mixing phase of DWF by in situ measurements (Gascard 1978). Their crests lean backward, in relation to the direction of the moving current, which is caused by the fact that disturbances drift downstream with the mean current. Those near the jet maximum move faster than disturbances away from the jet axis. This behavior was first exhibited by Griffiths and Linden (1981) in a set of laboratory experiments. During months 3 and 4 , a second phase of instability starts (Fig. 8d), which leads to six larger $(\sim 80 \mathrm{~km})$ and backward-leaning meanders. Meanders slowly decay after the end of the forcing period as the newly formed water sinks.
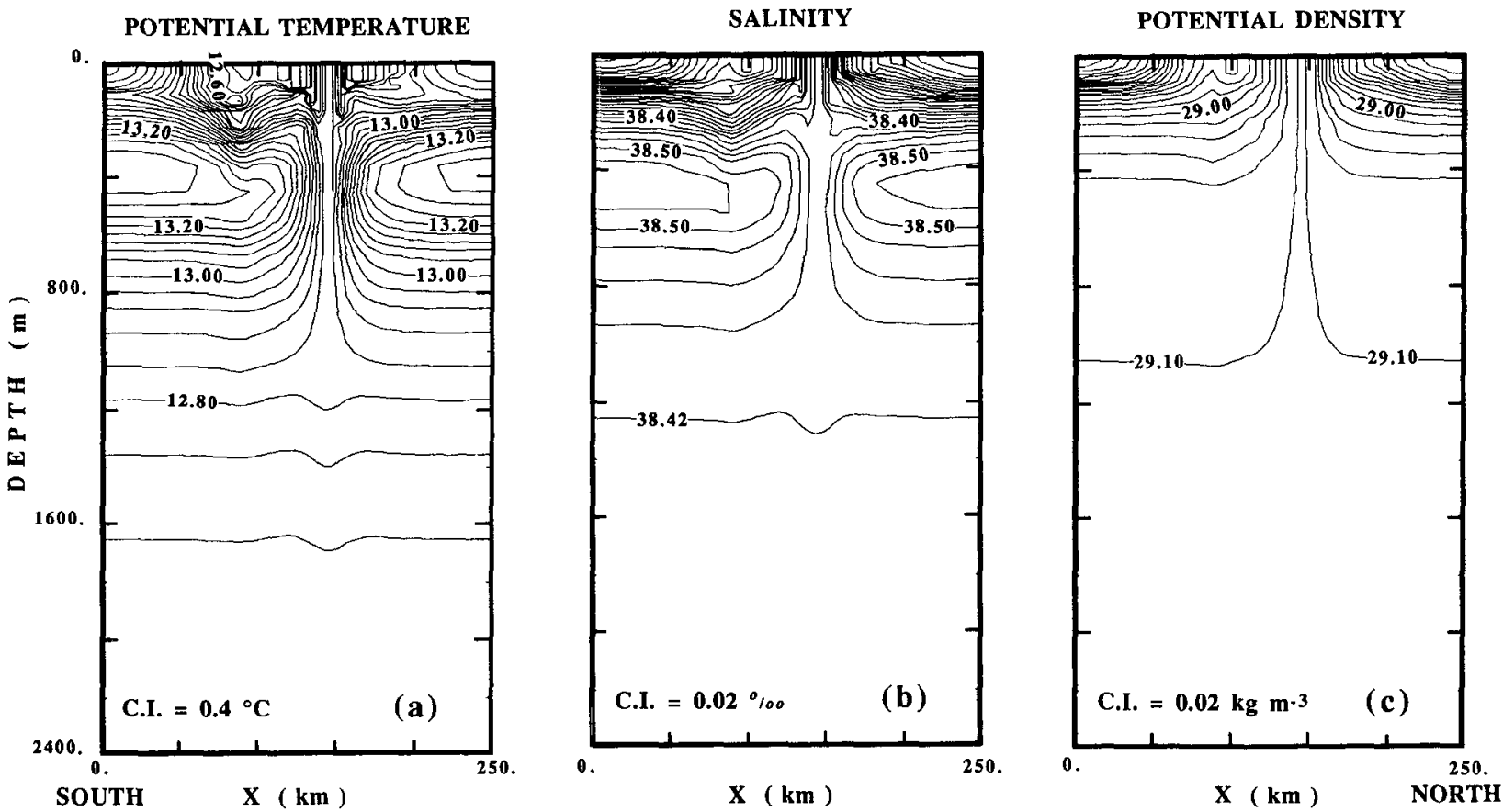

FIG. 6. North-south vertical section in the center of the forcing area $(x=300 \mathrm{~km})$ at the end of month $3:$ (a) potential temperature, (b) salinity, and (c) potential density ( $\sigma_{\theta}$ units). The contour intervals (CI) are as indicated. 
POTENTIAL TEMPERATURE

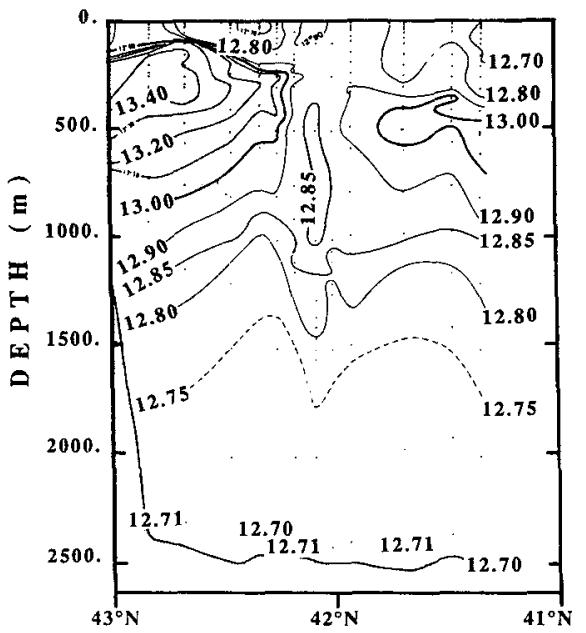

(a)
SALINITY

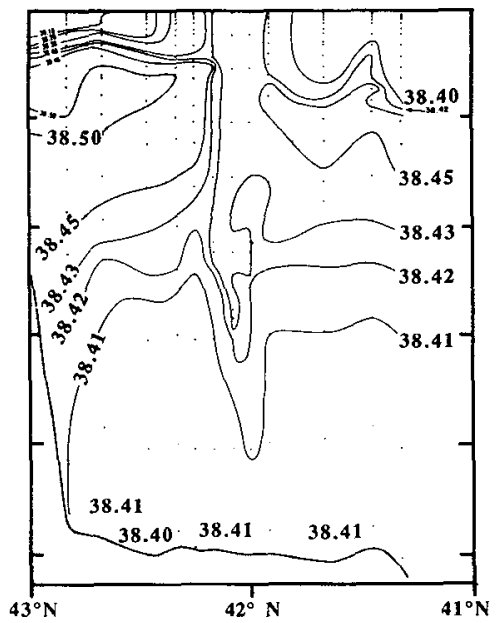

(b)
POTENTIAL DENSITY

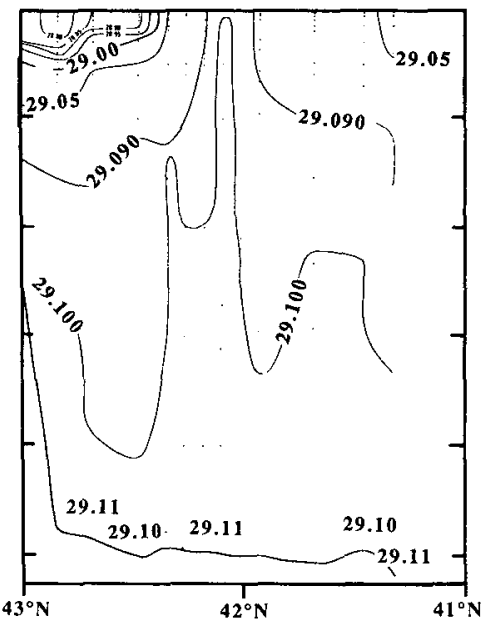

(c)

FIG. 7. North-south vertical section along $6^{\circ} \mathrm{E}$ during MEDOC 69, 15-19 February (from Tchernia and Fieux 1971):

(a) potential temperature, (b) salinity, and (c) potential density ( $\sigma_{\theta}$ units).

As soon as the $40-\mathrm{km}$ meanders appear, they start propagating in the cyclonic direction with a speed of $1.8 \mathrm{~cm} \mathrm{~s}^{-1}$ (Fig. 9). This phase speed is about one-fifth of the mean surface velocity, as was found by Gascard (1978) when he applied Tang's (1975) analytical model of baroclinic instabilities to this specific problem. The meander phase speed changes to $0.95 \mathrm{~cm} \mathrm{~s}^{-1}$ when the wavelength doubles from 40 to $80 \mathrm{~km}$ (Fig. 9). The development of both types of meanders is evident throughout the water column and their amplitude decreases with depth. The phase deflects in the upstream direction as the depth increases (Fig. 10a): the surface crests lag the deep crests by $\lambda / 4$, as was observed during MEDOC cruises (Gascard 1978). Since the vertical shear of the density current is positive (from the thermal wind relationship), this vertical phase structure is characteristic of baroclinic instability processes (Pedlosky 1987). It is thus inferred that the development of the meanders occurs through such a process, i.e., through a transfer from the potential energy of the density current to the eddy kinetic energy of the meanders. Further support for this expectation can be found in section 4 through detailed energy considerations concerning the dynamics of similar meanders in a periodic channel.

A cell of downward velocity (downward cell) appears centered on the surface density crest of the meander while a cell of upward velocity (upward cell) appears between two density crests (Fig. 10). These cells extend throughout the water column without vertical phase lag, so that in the deep layers the downward (upward) cell is on the upstream (downstream) side of the meander. These cells are small: their diameters are $\sim 10 \mathrm{~km}$ $(\sim 20 \mathrm{~km})$ for the downward (upward) cell of a $40-$ $\mathrm{km}$ meander and they are about twice as large for a $80-\mathrm{km}$ meander. Maximum vertical velocities are found between 200 and $300 \mathrm{~m}$ (i.e., in the pycnocline) where its typical value is $\pm 0.5 \mathrm{~mm} \mathrm{~s}^{-1}$ (Fig. 10d), but can sometimes exceed $-2.0 \mathrm{~mm} \mathrm{~s}^{-1}$ (i.e., $\sim 170 \mathrm{~m}$ $\mathbf{d}^{-1}$ ) in downward cells. The subsurface maximum of vertical velocity in the cells induces surface convergence and deep divergence in a downward cell and the inverse in a upward cell. Thus, cyclonic and anticyclonic perturbations (eddies) of the surface and deep horizontal currents, respectively, are generated in a downward cell. The opposite, surface anticyclonic and deep cyclonic perturbations, appears in an upward cell. Following the mean surface circulation, anticyclones are found to the left and cyclones to the right in the upper layer (top $200 \mathrm{~m}$ ), while cyclones are found to the left and anticyclones to the right in the deeper layers (below $300 \mathrm{~m}$ ) (Fig. 11). Such a distribution of eddies tends to generate a surface anticyclonic flow and a deep cyclonic flow, in opposition to the mean flow, and thus diminishes the vertical shear of the mean circulation.

Isothermal and isohaline surfaces are tilted upward and downward within the cells (Fig. 10) with an amplitude that can exceed $200 \mathrm{~m}$ and $400 \mathrm{~m}$ for the 40 and $80-\mathrm{km}$ meanders, respectively. In opposition to the isopycnal surfaces, the maximum of upward displacement of isothermal and isohaline surfaces (i.e., the crests of temperature and salinity) are shifted downstream as the depth decreases. This shift is the result of the relative magnitude of the phase speed $C$ of meanders and the along-meander component $U$ of the horizontal velocity. Below $300 \mathrm{~m}, C$ is greater than $U$ : a particle of water advected by the current sees the meander passing by from upstream to downstream (i.e., from west to east in Fig. 10). So, the crests of temperature and salinity are on the upstream side of 

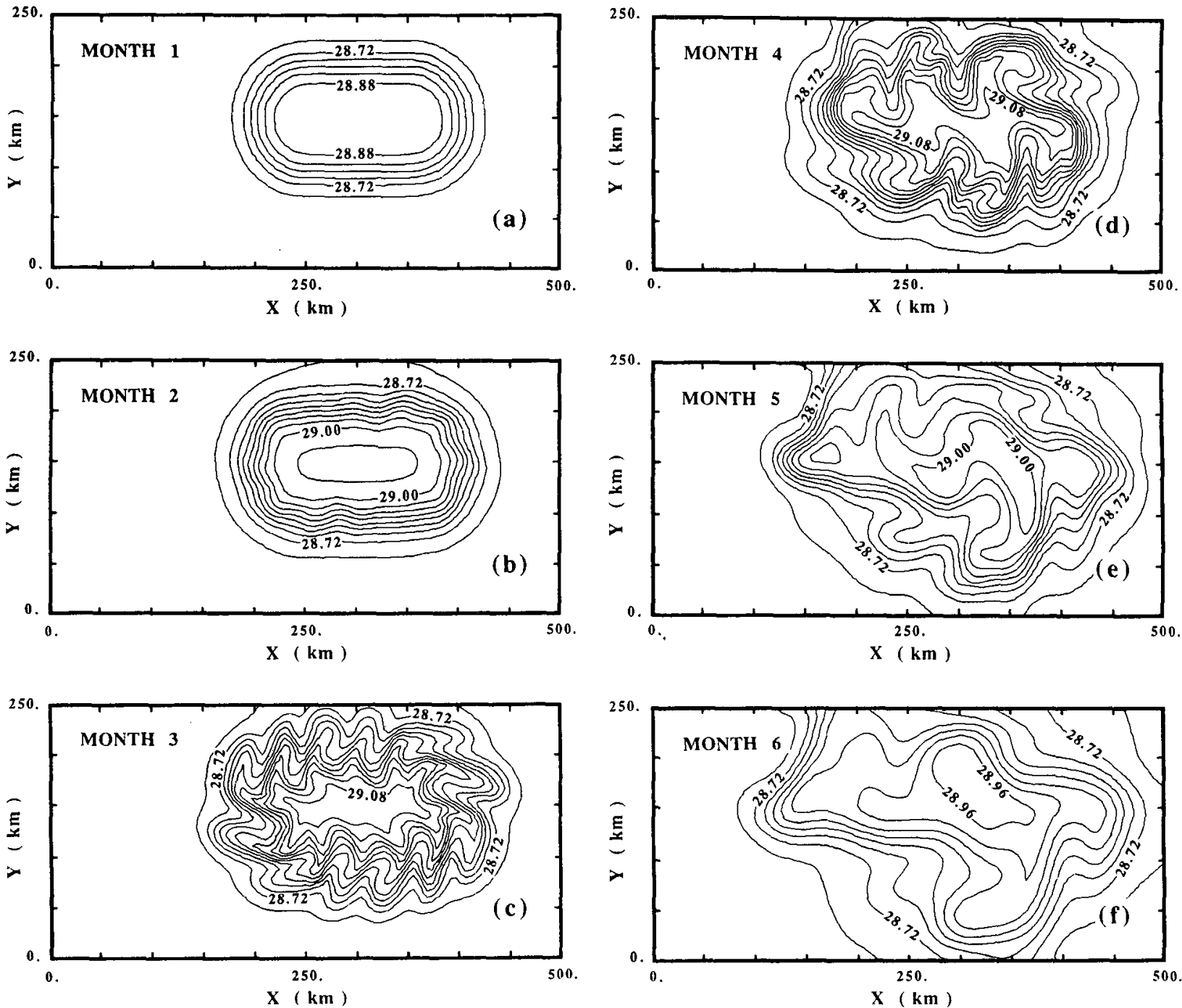

FIG. 8. Monthly patterns of sea surface density ( $\sigma_{\theta}$ units). Contour interval equals $0.02 \mathrm{~kg} \mathrm{~m}^{-3}$.

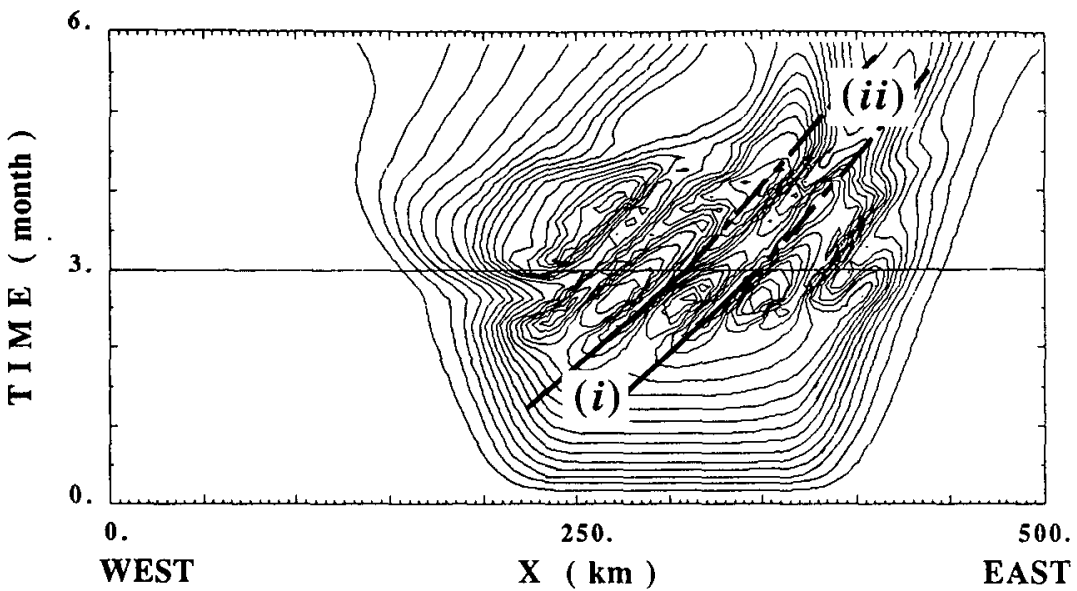

FIG. 9. West-east section of surface density ( $\sigma_{\theta}$ units) in the southern part of the forcing area (i.e., $y=90 \mathrm{~km}$ ) versus time. Straight lines indicate the phase speed of $(i) 40-\mathrm{km}$ and (ii) $80-\mathrm{km}$ meanders: $1.8 \mathrm{~cm} \mathrm{~s}^{-1}$ and $0.95 \mathrm{~cm} \mathrm{~s}^{-1}$, respectively. Contour interval equals 0.02 $\mathrm{kg} \mathrm{m}^{-3}$. 

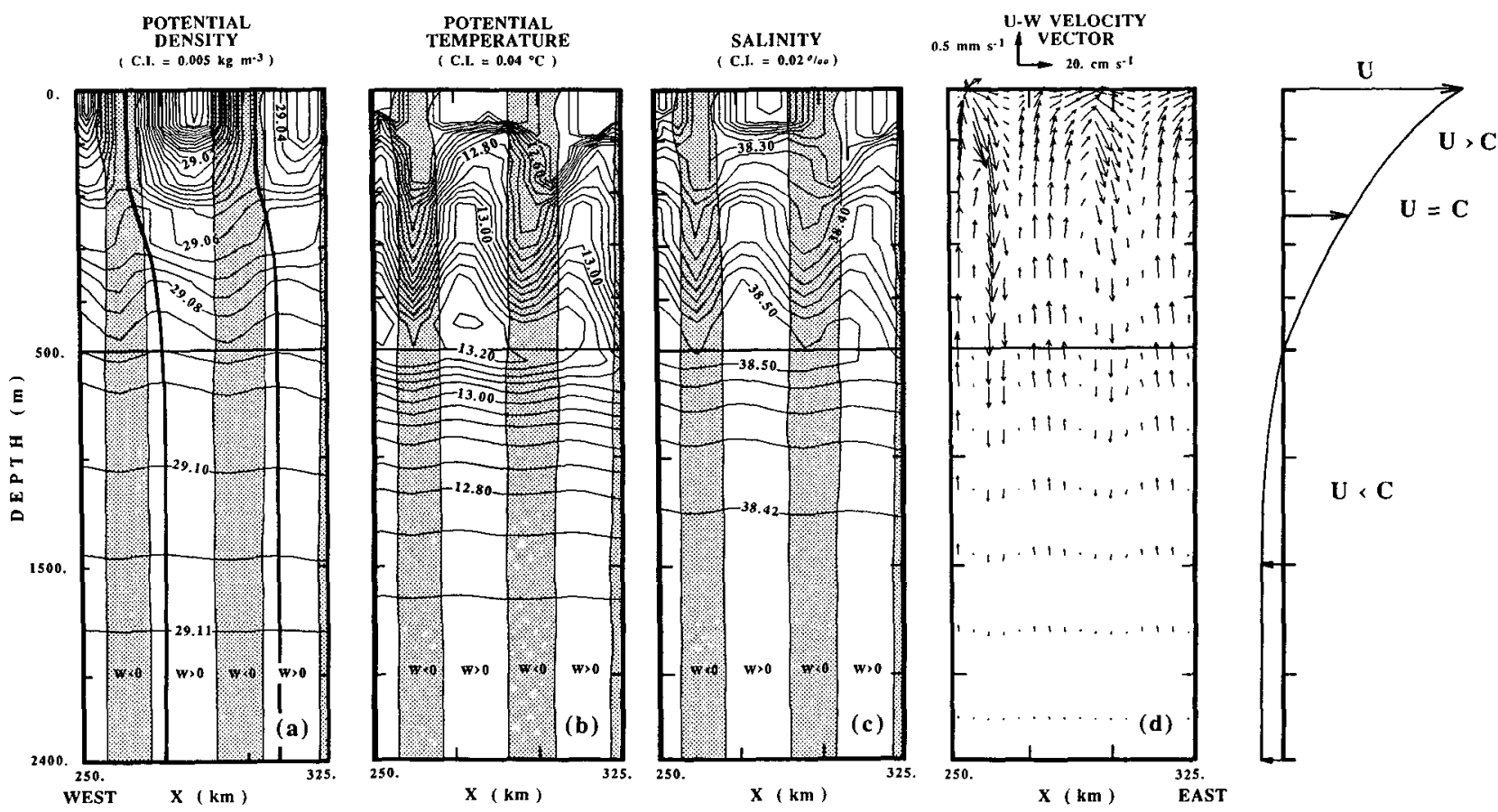

FIG. 10. West-east vertical section in the southern part of the forcing area ( $x=250$ to $325 \mathrm{~km} ; y=120 \mathrm{~km})$ at the end of month $3:$ (a) potential density ( $\sigma_{\theta}$ units); (b) potential temperature; (c) salinity; and (d) velocity, which is a combination of the zonal and vertical components of the velocity (maximum vertical velocity is $0.7 \mathrm{~mm} \mathrm{~s}^{-1} \approx 60.0 \mathrm{~m} \mathrm{~d}^{-1}$ ). Shaded areas are cells of downward velocity. A schematic view of the vertical profile of the along-meander component $U$ of the horizontal velocity is given on the right. $U$ is compared to the phase speed $C$ of the meanders. Solid lines on (a) indicate the crests of density maximum.

the upward cell. Between 300 and $200 \mathrm{~m}, C$ and $U$ are nearly equal. The crests are in the center of the upward cell. Above $200 \mathrm{~m}, C$ is less than $U$ : the crests are shifted to the downstream side of the upward cell. Note that above $100 \mathrm{~m}$ the vertical velocity is very small in comparison to the horizontal component, and pockets of relatively warm and fresh water advected from the periphery of the homogeneous column appear on the top of the upward cell (Fig. 10).

In the horizontal, such vertical displacements cause phase lags that vary with depth, between extrema of temperature, salinity, and density in the meander development area. In the top $100 \mathrm{~m}$, both the vertical velocity and the vertical gradient of the characteristics of the seawater are weak. The crests of the density and salinity maxima are in phase with the crest of the temperature minimum. But, between 100 and $400 \mathrm{~m}$, strong vertical velocities are associated with maximum vertical gradients of both temperature and salinity (Fig. 2). Upward motion advects the warm and salty LIW, while downward motion advects cold and fresh surface water (Fig. 10). The crests of both the temperature and salinity maxima are deflected in the downstream direction with respect to density crests, while the crests of the temperature and salinity minima are deflected in the upstream direction. This results in a phase lag between temperature and salinity at these depths in the meandering region such that the thermal and haline crests are in quadrature (Fig. 11). Such a phase lag between thermal and haline fronts has been observed in the MEDOC area during the violent mixing phase of DWF (Gascard 1978). In some cases, his observations indicated a phase lag up to the surface, which shows that the vertical motion can be strong enough to advect the LIW up to the surface.

After the forcing stops, the neutrally stable column is no longer maintained. The top $800 \mathrm{~m}$ of the column sinks within two weeks, due to the $80-\mathrm{km}$ meander activity, and spreads laterally in deeper levels, while the subsurface temperature and salinity maximum of the LIW reappears in the center of the forcing area (Fig. 5). During these two weeks, the vertical velocities within the eddies associated with the meanders are still very high (from 0.2 up to $2.0 \mathrm{~mm} \mathrm{~s}^{-1}$ ), while they are less than $0.05 \mathrm{~mm} \mathrm{~s}^{-1}$ after 4.5 months. Such rapid restratification of surface water associated with $\sim 20$ $\mathrm{km}$-diameter eddies is consistent with the observations made during the sinking and spreading phase of DWF (Stommel 1972; Sankey 1973).

A dome of isopycnal surfaces is formed as surface waters are restratified, while meanders are damped through model dissipative processes. The dome slowly propagates northwestward at a speed of a long Rossby wave $\left(0.3 \mathrm{~mm} \mathrm{~s}^{-1}\right)$ in interaction with the nonlinear effects (Bretherton and Karweit 1975). The westward propagation has been ascribed to the $\beta$ effect by Crépon 

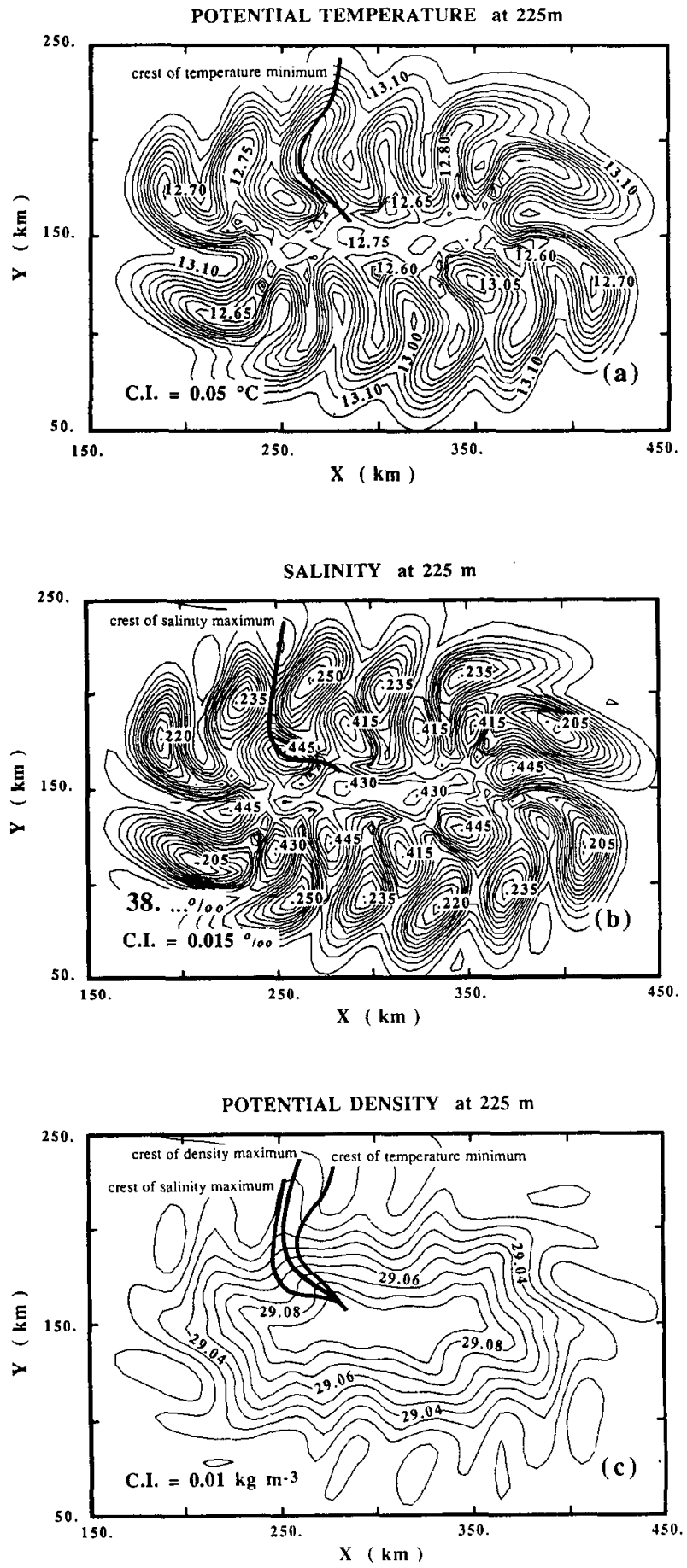

Fig. 11. Horizontal section at $225 \mathrm{~m}$ (i.e., just above the LIW) after 3 months: (a) potential temperature, (b) salinity, and (c) potential density ( $\sigma_{\theta}$ units). The contour intervals $(\mathrm{Cl})$ are as indicated. Crests of the salinity maximum (temperature minimum), which coincide with crests of the density maximum within the column, are displaced downstream (upstream) when approaching the cells of upward (downward) motion on the downstream (upstream) side of the meanders. This is due to upward advection of the warmer and saltier Levantine Intermediate Water and to downward advection of relatively cold and fresh water originating from the surface. et al. (1989). After six months, the $1029.05 \mathrm{~kg} \mathrm{~m}^{-3}$ isopycnal surface (Fig. 5a) is $\sim 100 \mathrm{~m}$ higher than its initial value and is consistent with the observations (Crépon and Boukthir 1987).

The interaction between the thermodynamic and dynamic responses is summarized in Fig. 12, which shows the time evolution of the basin-average conversion from potential to kinetic energy $(P \rightarrow K)$, compared to those of the loss of potential energy through the convective adjustment process (CP). $P \rightarrow K$ and $\mathrm{CP}$ are defined by the following expressions:

$$
\begin{aligned}
P \rightarrow K & =\frac{1}{V} \iiint_{v} \nabla p \cdot \mathrm{U} d v \\
\mathrm{CP} & =\frac{1}{V} \iiint_{v}\left(\rho_{b}-\rho_{a}\right) g z d v,
\end{aligned}
$$

where $\rho_{b}$ and $\rho_{a}$ are the density fields before and after the convective adjustment algorithm is applied and $V$ is the volume of the model basin. Here CP is not intrinsically defined but depends on the assumed reference depth (here the surface), as for the potential energy. It can be viewed as a suitable indicator of the basin-averaged strength of convection through the convective adjustment process.

During the first 2 months the response of the ocean is linear, $P$ is converted very slowly into $K$, while $\mathrm{CP}$ continuously increases as the depth of the convection becomes larger. Between months 2 and 3, the conversion from $P$ to $K$ increases as the $40-\mathrm{km}$ meanders develop. Meanders advect light water from the periphery to the center of the homogeneous column. Thus,

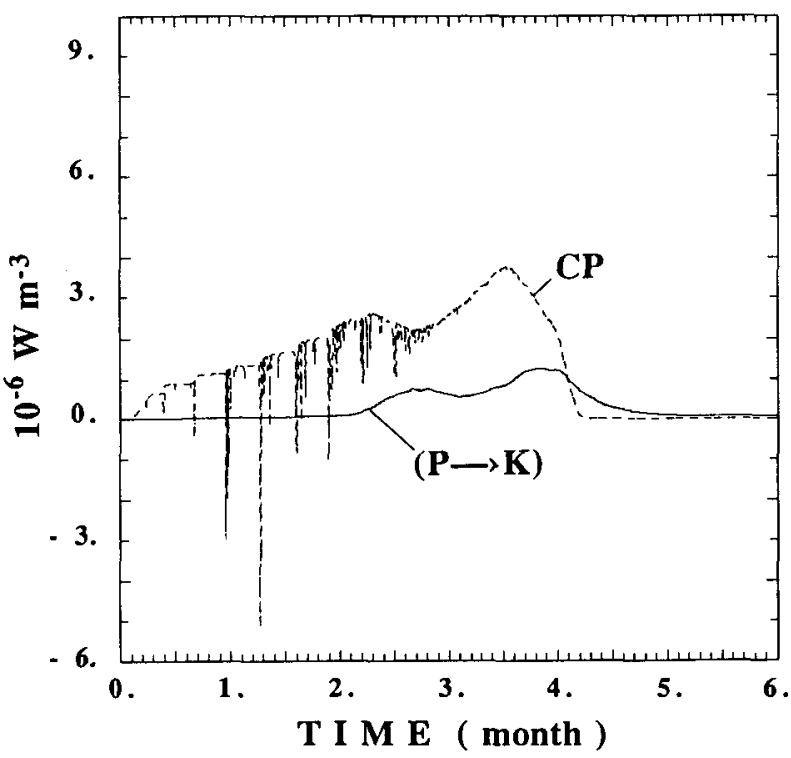

FIG. 12. Time variation of the conversion from potential to kinetic energy $(P \rightarrow K)$ and of the loss of potential energy through the convective adjustment process $(\mathrm{CP})$. 
CP slightly diminishes to reach a first minimum at 2.7 months, i.e., at the very moment $P \rightarrow K$ presents a relative maximum. Between months 3 and 4.5 , a second period of growth of $P \rightarrow K$ occurs that corresponds to the $80-\mathrm{km}$ meander development. The horizontal advection caused by these meanders restratifies the surface water of the column and strongly diminishes CP. After 4 months, the forcing stops and CP becomes zero. This behavior of both $P \rightarrow K$ and CP emphasizes that meander development tends to limit the depth of convection.

A remarkable feature in the time evolution of $\mathrm{CP}$ is the presence of negative peaks, which means that the vertical convective adjustment process sometimes provides potential energy to the model basin. These peaks appear at the very moment the convective adjustment algorithm involves a new vertical level. At this time, the mixing of two different water masses occurs, which leads to a new water mass whose density is higher than the arithmetic mean density of the two previous water masses. This phenomenon, called cabbeling (Csanady 1982), is a consequence of the nonlinearity of the equation of state. The greatest peaks in $\mathrm{CP}$ are found between 0.5 and 2.5 months, i.e., when the difference of the $T-S$ characteristics between the neutrally stable column and the water below (here the LIW) is the largest (Fig. 4). At the end of the forcing period, cabbeling has induced $5 \mathrm{~m}$ of extra deepening of the column. This value is very small in comparison with the 1000-meter thickness of the column. Cabbeling, therefore, appears to play a negligible role in DWF in the NWM Sea, unlike DWF at high latitudes, where the seawater is colder and the nonlinearity in the equation of state is thus more important (McDougall 1983).

\section{c. Induced mean flow}

A mean current can be defined by zonally averaging the current from $x=260 \mathrm{~km}$ to $x=340 \mathrm{~km}$. The meridional component of this mean current is one to two orders of magnitude smaller than its zonal component; therefore, we consider the zonal component to represent the mean current generated by the thermohaline forcing. Figure 13 shows sequential patterns of this mean current in the coastal area (i.e., between the center of the forcing area and the northern coast). As mentioned previously, during the first 2 months the response of the ocean to the thermohaline forcing is in good agreement with the linear theory (Crépon et al. 1989). A strong $\left(\sim 10.0 \mathrm{~cm} \mathrm{~s}^{-1}\right)$ westward (i.e., cyclonic) surface current is generated above the pycnocline level (i.e., $200 \mathrm{~m}$ ), while below this level a weaker $\left(0.2 \mathrm{~cm} \mathrm{~s}^{-1}\right)$ and nearly vertically homogeneous eastward (i.e., anticyclonic) current appears. Meander development induces a vertical mixing of momentum centered at the edge of the forcing area, and the current flows westward throughout the water column near $y$ $=200 \mathrm{~km}$ in month 3 and until the end of the sixth month (Fig. 13). Vertical mixing occurs in the very area where the vertical shear of the current was maximum before the meanders developed. Thus, the meanders tend to diminish the vertical shear, which is another indication that meanders develop through a baroclinic instability process. The vertical mixing of
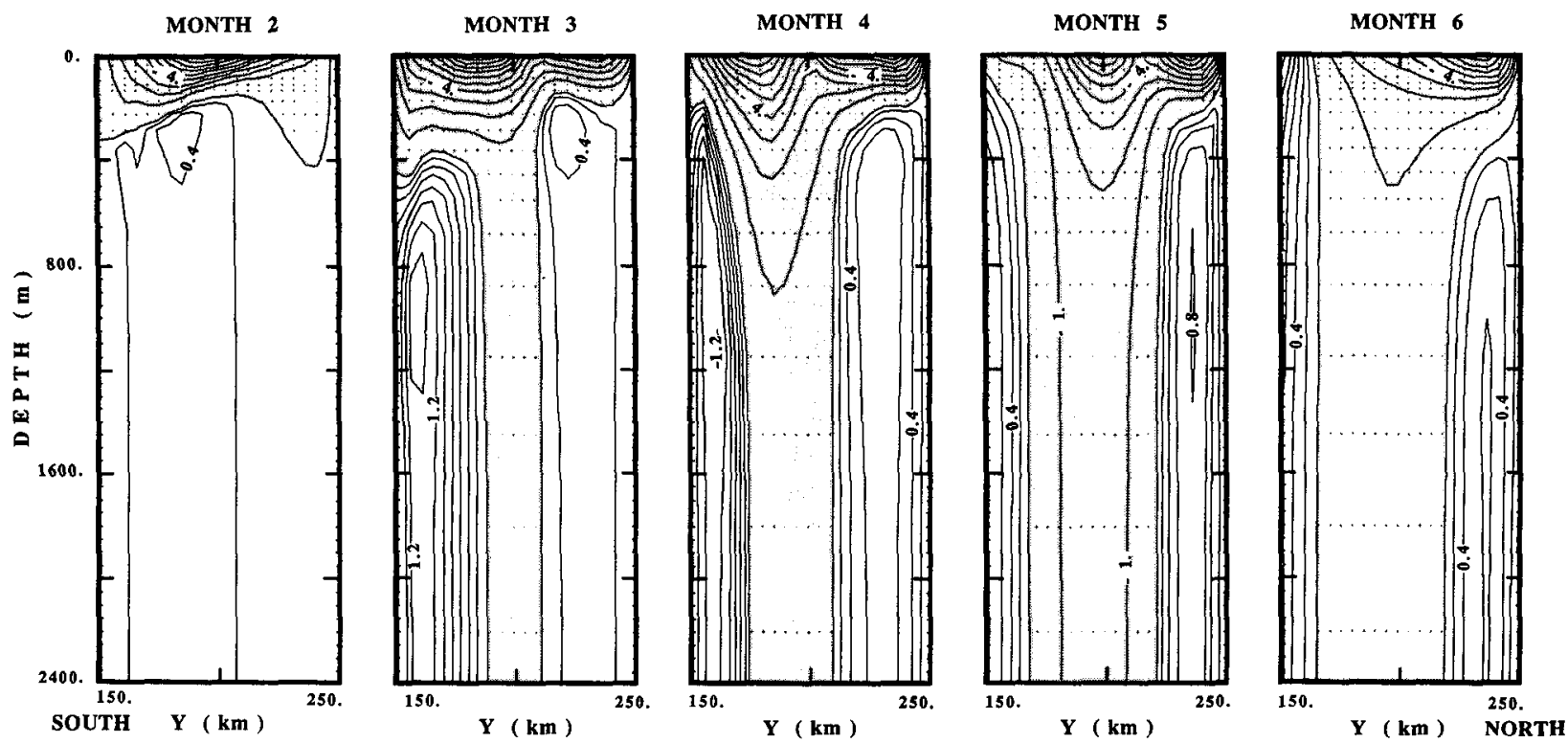

FIG. 13. Monthly vertical sections between the center of the forcing area and the northern coast ( $y=150$ to $250 \mathrm{~km}$ ) of mean (averaged from $x=260$ to $340 \mathrm{~km}$ ) zonal velocity. Flow to the west (cyclonic) is shaded. The contour interval is $1 \mathrm{~cm} \mathrm{~s}^{-1}$ for the westward flow and $0.2 \mathrm{~cm} \mathrm{~s}^{-1}$ for eastward flow. 
the surface current is consistent with the horizontal eddy distribution (Fig. 11). The double core of the surface current in Fig. 13 (months 3, 4, and 5) is the result of the meandering structure of the current. It slowly moves northward as the dome of isopycnal surfaces propagates northwestward. After six months, the mean current defines a cyclonic circulation throughout the water column, except in the coastal region where a deep weak countercurrent still persists under the maximum of the surface current.

The horizontal volumetric transport of the water masses that flow between the southern edge of the surface westward current and the northern coast has been computed during experiment I. Figure 14 shows the depth-integrated transport in terms of the westward and eastward components of the transport that correspond to the cyclonic current and deep anticyclonic countercurrent, respectively. During the first two months, the transport has the same magnitude in both gyres as is expected from the linear theory (Crépon et al. 1989). This balance is destroyed by the vertical mixing of the westward current induced by the meander activity, and a net westward transport first appears at month 3 . It reaches a maximum of $1.2 \mathrm{~Sv}(1 \mathrm{~Sv}$ $\equiv 10^{6} \mathrm{~m}^{3} \mathrm{~s}^{-1}$ ) near 4.7 months. Note that both westward and eastward transports show a relative maximum at months 3 and 4.5-that is, at the end of the development period of the $40-\mathrm{km}$ and $80-\mathrm{km}$ meanders, respectively.

The winter thermohaline forcing induces a maximum westward transport of $2.2 \mathrm{~Sv}$ with $1.2 \mathrm{~Sv}$ in the

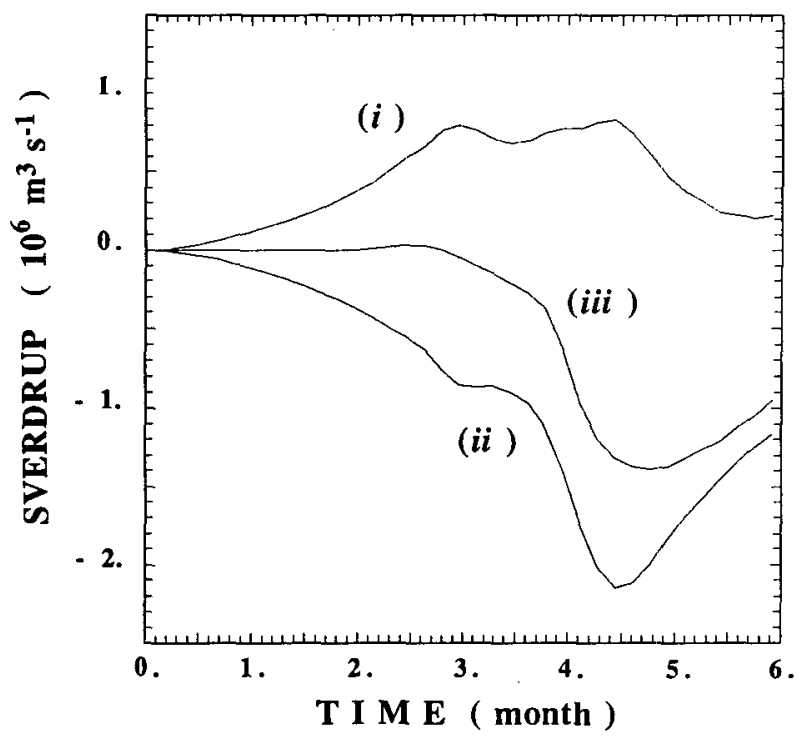

FIG. 14. Time evolution of the horizontal volumetric transport of water between the center of the forcing area and the northern coast: (i) transport of the eastward deep countercurrent, (ii) transport of the westward and mainly surface current, and (iii) vertical averaged transport. top $700 \mathrm{~m}$. It therefore could be responsible for the increase of $\sim 1 \mathrm{~Sv}$ in the surface westward LiguroProvencal Current in winter that has been estimated from observations by Béthoux et al. (1982).

\section{Experiment II: Energetics of unstable thermohaline- forced waves in a periodic channel}

The problem solved in experiment $I$ is not suitable for an evaluation of the $e$-folding time of the meander growth nor for a study of energy transfers involved in their evolution. It is a forced problem that never reaches a state of statistical equilibrium, and its geometry is rather complicated. The time-average mean current cannot be defined with any correct physical meaning, and a definition of the space-mean current is problematic. Thus, experiment II has been designed specifically to allow a meaningful definition of the space-average current. This experiment is similar to experiment $I$, but in a zonal periodic channel (Fig. 3c). It is expedient for a comparison to meander development of experiment I, and useful information can be gained on the energetics of the meanders, which are of the same nature in both experiments.

Figure 15 shows the surface density after 2,3 , and 4 months of thermohaline forcing. The response of the ocean to the forcing is almost the same as in experiment I. During the linear period (month 0 to 2), a zonal baroclinic current is driven by the horizontal density gradient generated by the meridional variation in the forcing, while a neutrally stable area is formed along the southern coast. This current becomes unstable after 2 months (Fig. 15), and two successive meander-development events occur on the northern side of the neutrally stable area. The $T-S$ characteristics of the neutrally stable area (not shown here) at first have the same time evolution as in experiment $I$, but after the third month differences appear. Along the southern coast, the neutrally stable area reaches the bottom. This is because meander amplitude is smaller in experiment II than in experiment I, and thus meanders do not block very deep convection at the southern coast.

\section{a. Energy evolution}

Mean quantities (denoted by an overbar) are defined by a zonal average over the entire basin and eddy quantities (denoted by a prime) are defined as the departure from their zonal-averaged values. For example, the exact formula for the zonal velocity is

$$
\begin{aligned}
\bar{u}(y, z, t) & =\frac{1}{L} \int_{0}^{L} u(x, y, z, t) d x \\
u^{\prime}(x, y, z, t) & =u(x, y, z, t)-\bar{u}(y, z, t)
\end{aligned}
$$

where $L$ is the zonal length of the channel.

We define the channel-averaged values of the po- 

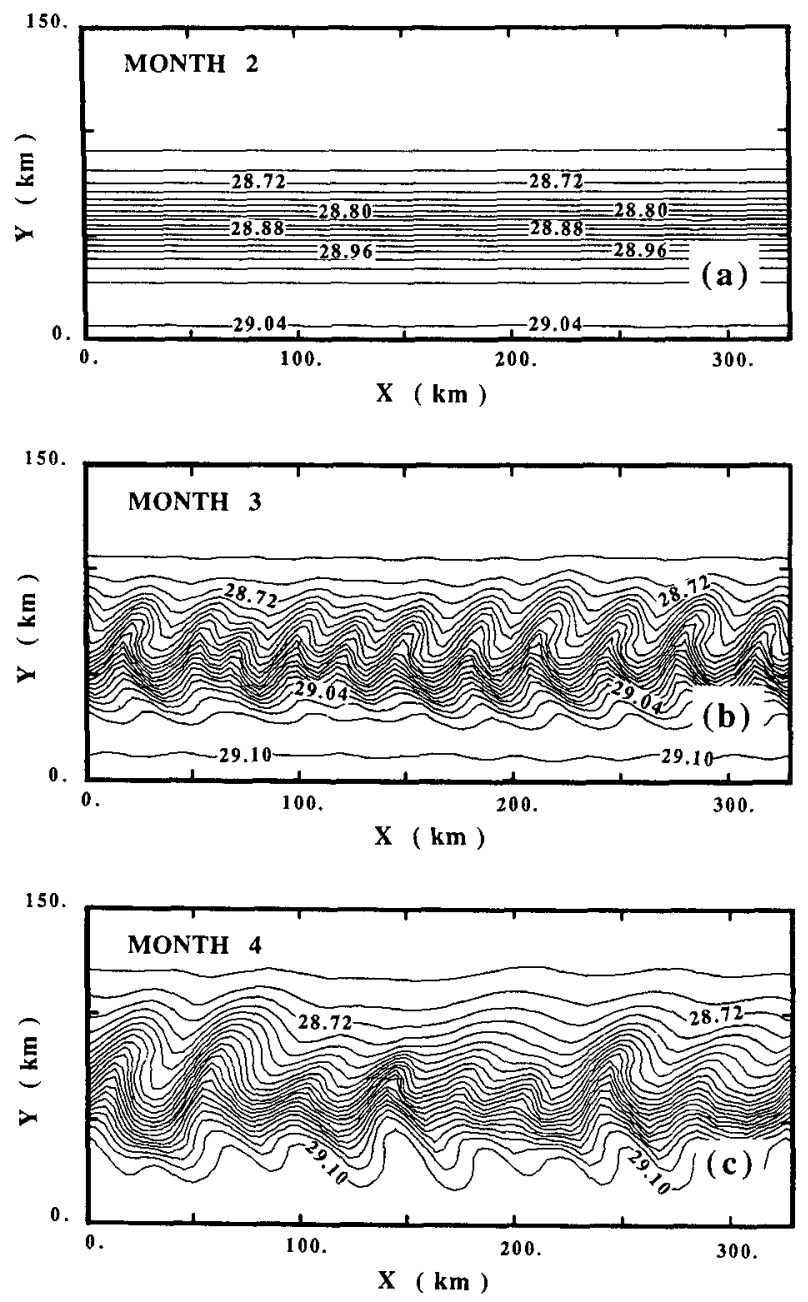

FIG. 15. Monthly patterns of sea surface density ( $\sigma_{\theta}$ units) for experiment II. Contour interval equals $0.02 \mathrm{~kg} \mathrm{~m}^{-3}$.

tential energy $(P)$, the horizontal mean (zonally averaged) kinetic energy $\left(K_{m}\right)$, and the horizontal eddy kinetic energy $\left(K_{e}\right)$ by the following expressions:

$$
\begin{aligned}
P & =\frac{1}{A_{y z}} \iint \bar{\rho} g z d y d z-P_{0} \\
K_{m} & =\frac{1}{A_{y z}} \iint \frac{1}{2} \rho_{0}\left(\bar{u}^{2}+\bar{v}^{2}\right) d y d z \\
K_{e} & =\frac{1}{A_{y z}} \iint \frac{1}{2} \rho_{0}\left(\overline{u^{\prime 2}}+\overline{v^{\prime 2}}\right) d y d z
\end{aligned}
$$

where $P_{0}$ is the initial potential energy and $A_{y z}$ is the area of a meridional channel section.

Figure 16 shows the time evolution of $P, K_{m}$, and $K_{e}$ during experiment II. We first note that the level of potential energy is at least three orders of magnitude larger than the levels of kinetic energies. In the model basin $P$ accumulates quasi-steadily as surface waters become more dense due to the thermohaline forcing, and it becomes nearly steady when the forcing stops (i.e., after 4 months). The redistribution of mass that results from convection, horizontal and vertical advections, or internal friction induces variations of $P$ that are some orders of magnitude smaller than those induced by the forcing, and they do not appear on the log scale of Fig. 16.

The meridional density gradient (front) generated by the thermohaline forcing strengthens (deepens) with respect to time. The resulting zonal density current is steadily accelerated, so that $K_{m}$ increases as $t^{2}$. After the forcing stops, $K_{m}$ slowly diminishes under dissipative effects.

The level of eddy kinetic energy is about three orders of magnitude smaller than the mean during the first two months. It is maintained by the random part of the forcing function (Fig. 3), which induces small meridional fluctuations of the density current. During the first months, $K_{e}$ exhibits peaks that are related to convective events, which will be discussed in the next subsection. After 1.5 months $K_{e}$ starts increasing. Its growth is exponential until 2.8 months, as might be predicted by linear theory (Pedlosky 1987). At the beginning of this growth period, the meanders have small amplitude, and linear instability theory is applicable. Using this, we calculate an $e$-folding time of 11.5 days, about four times greater than the $e$-folding time estimated from observations (Gascard 1978). This difference is due to the horizontal dissipation and is further discussed in section $4 \mathrm{c}$.

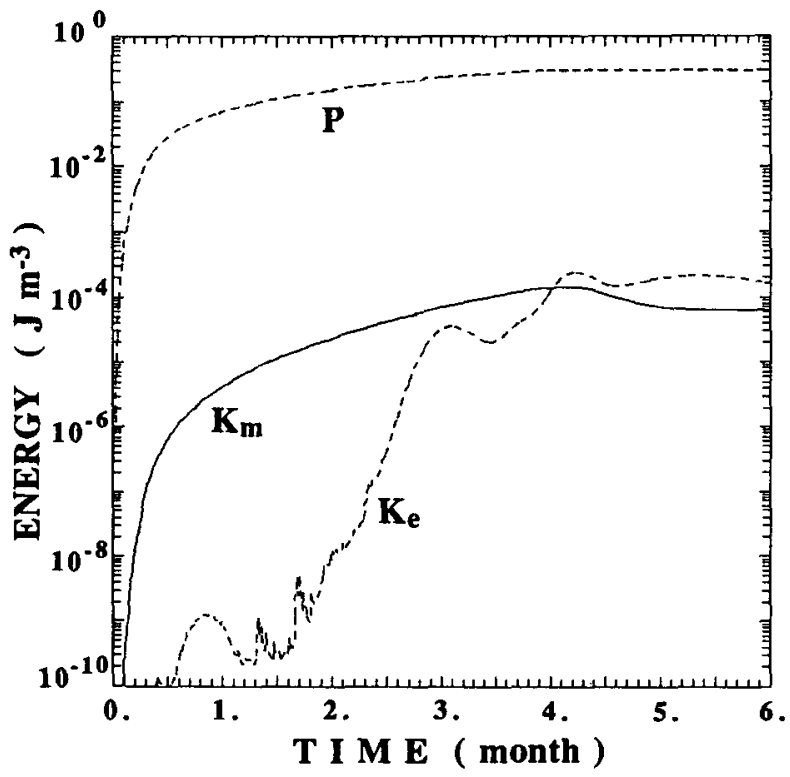

FIG. 16. Time evolution of channel-averaged potential energy $(P)$ and mean $\left(K_{m}\right)$ and eddy $\left(K_{e}\right)$ kinetic energies for experiment II. 
At 3.1 months, $K_{e}$ reaches a relative maximum then begins to decrease under the effects of dissipation until 3.45 months. At this moment, the second event of meander growth starts and lasts for 0.8 months. This event is not correlated with the end of the forcing period, yet its growth period and the level achieved are slightly smaller than those it would have if the forcing acted longer than 4 months. After 4.2 months, $K_{e}$ experiences oscillations of small amplitude and low frequency about the level achieved during the second growth period. Such behavior is characteristic of the long-term evolution of baroclinic instabilities in a forced and rather dissipative problem (Pedlosky 1987; Boudra et al. 1988).

\section{b. Energetic balances}

The assumption that baroclinic instability processes prevail is further supported by considering the energetic balances of potential, mean kinetic, and eddy kinetic energies. Multiplying the density conservation equation by $g z$ and averaging over the channel gives the equation for $P$. The kinetic energy equations can be derived from the scalar product of (1) by $\overline{\mathbf{U}}_{h}=(\bar{u}, \bar{v})$ and by $\mathbf{U}_{h}^{\prime}$ $=\left(u^{\prime}, v^{\prime}\right)$, respectively, and then averaging the result over the channel (Orlanski and Cox 1973). The resulting equations can be written as:

$$
\begin{aligned}
(P)_{t} & =\mathrm{PS}+P \rightarrow K+\mathrm{VDP}+\mathrm{CP} \\
\left(K_{m}\right)_{t} & =K_{e} \rightarrow K_{m}+P \rightarrow K_{m}+D K_{m} \\
\left(K_{e}\right)_{t} & =K_{m} \rightarrow K_{\mathrm{e}}+P \rightarrow K_{e}+D K_{e} .
\end{aligned}
$$

In the above equations, $\left(K_{m}\right)_{t},\left(K_{e}\right)_{t}$, and $(P)_{t}$ are the time derivatives of mean kinetic, eddy kinetic, and potential energies, respectively, and PS is the potential energy supply by the thermohaline forcing, i.e., the time variation of $P$ due to the mass increase of the surface water induced by the forcing (this does not include the loss of $P$ due to the convective adjustment process, CP). Here $K_{m} \rightarrow K_{e}$ and $K_{e} \rightarrow K_{m}$ are derived from the nonlinear terms of (1). $K_{m} \rightarrow K_{e}$ is the barotropic conversion, i.e., the conversion of mean to eddy kinetic energy through the Reynolds stress interacting with the shear of the mean flow. It is shown (Orlanski and Cox 1973 ) that $K_{e} \rightarrow K_{m}$ is equal in magnitude to $K_{m} \rightarrow$ $K_{e}$ but opposite in sign, if total kinetic energy is conserved in the model basin (see the Appendix). $P \rightarrow$ $K_{m}$ and $P \rightarrow K_{e}$ are derived from the pressure gradient term of (1). $P \rightarrow K_{m}$ is the conversion from potential to mean kinetic energy, and $P \rightarrow K_{e}$ is the baroclinic conversion, i.e., the conversion from potential to eddy kinetic energy. Their sum, $P \rightarrow K$, is the total conversion of potential into kinetic energy. $D K_{m}$ and $D K_{e}$ are the dissipation of mean and eddy kinetic energy, respectively. VDP is the gain of potential energy through the vertical dissipation of density induced by eddy dif- fusivity of both temperature and salinity [always small in our experiments compared to the other terms of (12)]. CP is the loss of potential energy due to the convective adjustment process, as defined previously in (8).

Figure 17 shows the time evolution of each of the terms of (12). The potential-energy supply is nearly constant throughout the forcing period. It mainly serves to increase the potential energy of the basin, except for a non-negligible part lost in the convective adjustment process (CP). This loss increases with respect to time and presents a break at 2.8 months, which corresponds to the moment when all the well-stratified surface waters have been homogenized by convective processes. As in experiment I, CP has negative peaks that are related to cabbeling. Convective events raise the level of $K_{e}$ (Fig. 16) and induce high-frequency oscillations in the conversion of $P$ to $K_{m}$ (Fig. 18). These oscillations result from long internal gravity waves generated in the transient phase of the geostrophic adjustment due to the sudden convection from one vertical level to the next. Their period is $17 \mathrm{~h}, 08 \mathrm{~min}$, i.e., a little below the local inertial period $17 \mathrm{~h}, 56 \mathrm{~min}$ at $42^{\circ} \mathrm{N}$ ). Millot and Crépon (1981) have noted that such internal waves have always been observed in the NWM Sea, as a transient response to wind perturbations. The conversion $P \rightarrow K$ is always one order of magnitude smaller than $\mathrm{CP}$ (Fig. 17) and does not significantly affect $(P)_{t}$. The decreases in $P$ are almost all caused by the vertical

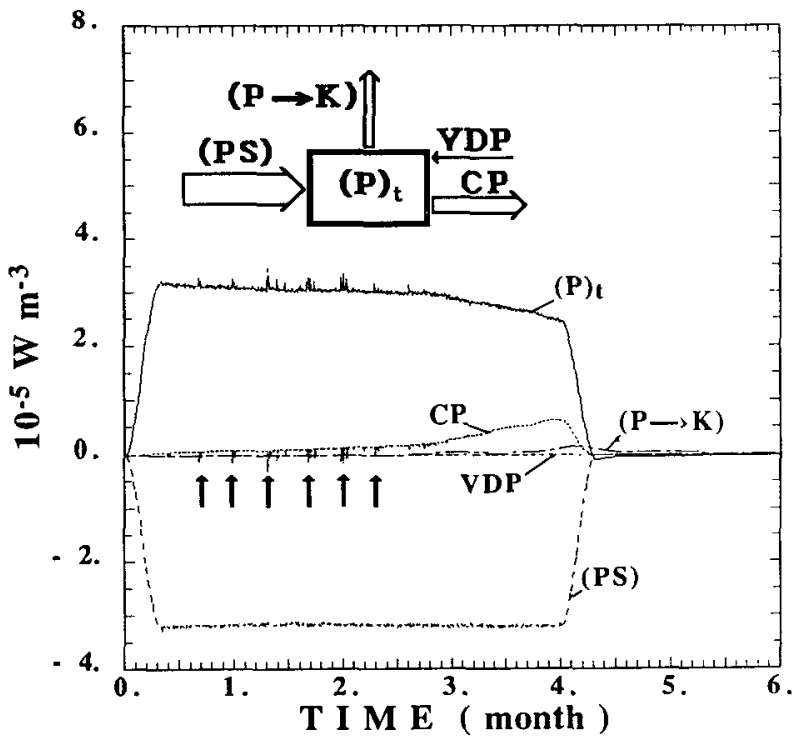

FIG. 17. Time evolution of the potential energy balance equation for experiment II. The time derivative $(P)_{t}$ of potential energy is given by the sum of: the potential energy supply by the thermohaline forcing (PS); the gain of potential energy through vertical dissipation (VDP); the loss of potential energy due to the convective adjustment process $(\mathrm{CP})$; and the conversion from potential to kinetic energy $(P \rightarrow K)$. Arrows indicate the occurrence of convective events. 


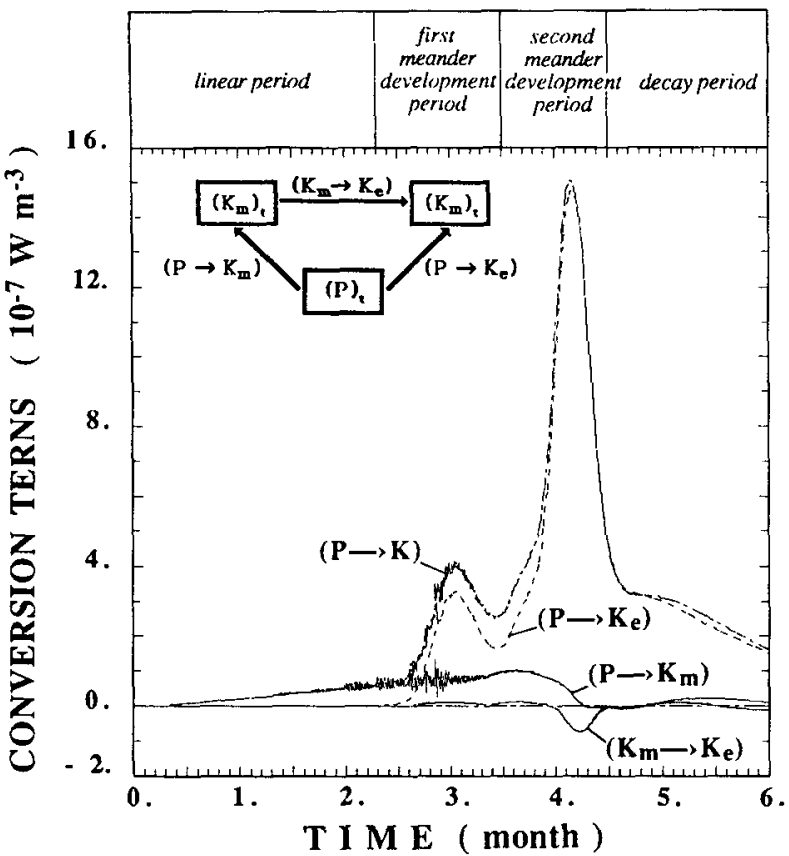

FIG. 18. Time evolution of the conversion terms between potential, mean kinetic, and eddy kinetic energies for experiment II. $K_{m} \rightarrow K_{e}$ is the conversion from mean to eddy kinetic energy, and $P \rightarrow K_{m}$ and $P \rightarrow K_{e}$ are the conversions from potential energy to mean kinetic and eddy kinetic energy, respectively. Their sum $(P \rightarrow K)$ is the total conversion from potential to kinetic energy.

convective adjustment process rather than by $P \rightarrow K$, which includes baroclinic adjustment processes. At the end of the forcing period, $P$ slowly decreases as it is converted into $K$, which is lost through the dissipative terms of (13) and (14).

Figure 18 shows the time evolution of the energy conversion terms between mean kinetic, eddy kinetic, and potential energies. The total conversion of potential to kinetic energy is in the direction of mean kinetic energy until 2.5 months. $P \rightarrow K_{m}$ increases linearly with respect to time. It induces an accumulation of $K_{m}$ at a rate proportional to $t^{2}$, while two-thirds of $P \rightarrow$ $K_{m}$ are lost through model dissipative processes (mainly the vertical dissipation ). A mean current is generated, which becomes unstable after 2.3 months. At this time, energy-conversion terms involving $K_{e}$ become significant. The meander energy $K_{e}$ is essentially provided by the baroclinic conversion $\left(P \rightarrow K_{e}\right)$, which exhibits two peaks at 3.1 and 4.2 months (i.e., at the end of each meander growth period). The large positive baroclinic conversion that occurs during each event of meander development leaves little doubt that the physical mechanism of amplification is a release of baroclinic instability. The positive barotropic conversion $\left(K_{m} \rightarrow K_{e}\right)$ that accompanies the first event is too weak to play a significant role in the growth of meanders. Moreover, this conversion becomes negative dur-

ing the second event, so that meanders provide energy to the mean current for this event.

The first period of meander development (month 2.3 to 3.5 ) does not significantly alter the conversion of $P$ to $K_{m}$. In fact, this experiment involves strongly forced dynamics: the thermohaline fluxes continuously force a meridional density gradient that directly strengthens the conversion of $P$ to $K_{m}$. For the second event (month 3.5 to 4.5 ), the $P \rightarrow K_{e}$ conversion is so strong that the rate of $P \rightarrow K_{m}$ slightly decreases after 3.8 months, while staying positive until the end of the forcing period. After month 4.5 , a decay period starts in which potential energy is converted into eddy kinetic energy, which is eventually dissipated.

Figure 19 shows the averaged energy transfer during the linear period (months 0 to 2.3 ), the first- (months 2.3 to 3.5 ) and second- (months 3.5 to 4.5 ) meander development periods, and the decay period (months 4.5 to 6 ). This figure concisely summarizes the differences in the dynamics at each period described above. It also shows the role of the horizontal dissipation of $K_{e}\left(D K_{e}\right)$, which nearly balances the conversion of $P$ to $K_{e}$. The importance of $D K_{e}$ is not surprising in such a strongly forced experiment where the only sink of energy is the dissipation. The paramount importance

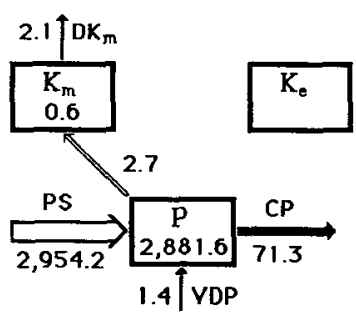

(a) linear period

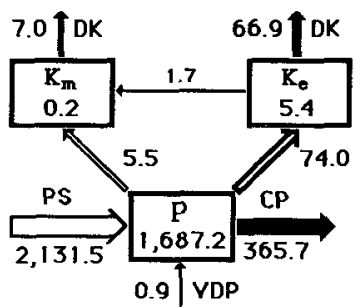

(c) second meander development period

FiG. 19. Energy flow diagrams showing energy transfers averaged for each of the four periods of Experiment II: (a) linear period, (b) first and (c) second meander development periods, and (d) decay period. Time-derivative values are shown under the name of each energy type. The values are in units of $10^{-8} \mathrm{~W} \mathrm{~m}^{-3}$. The solid arrows indicate the dissipation terms. Equations (12) to (14) define the terms of this diagram. 
of the horizontal dissipation in the model has motivated a sensitivity analysis of this parameterization, which is the subject of the next subsection.

\section{c. Sensitivity studies to horizontal dissipation}

Four sensitivity experiments (Table 2) have been performed to study the effect of horizontal dissipation. Multiplying by five the horizontal eddy viscosity and eddy diffusivity coefficients (experiment II-a) inhibits meander development during the experiment. By contrast, if the horizontal dissipation coefficients are reduced, meander development occurs earlier. This can be done either by using a higher order (experiment IIb) and thus more scale-selective operator, or by decreasing the grid spacing to $2 \mathrm{~km}$ (i.e., the third Rossby radius of deformation [Table 1] of the initial state), which allows smaller horizontal dissipative coefficients without computational instabilities (experiment II-c). The $e$-folding time is smaller than those of experiment II: $\sim 9$ days and $\sim 5$ days for experiments II-b and IIc, respectively. These values are closer to the 3-day $e$ folding time estimated from observations (Gascard 1978). In both cases, barotropic conversion stays relatively small in comparison to the baroclinic conversion, so that meanders always develop through a baroclinic instability process. But the nonlinearities are less dissipated than in experiment II. The net tendency of the nonlinearities is to rectify the mean current. $K_{m} \rightarrow$ $K_{e}$ reveals higher frequency oscillations around zero, which are characteristic of a relatively weak dissipative case (Pedlosky 1987). The amplitude of these oscillations are of the order of $\left(K_{m}\right)_{t} . K_{m}$ thus fluctuates in response to the barotropic conversion term. The depth to which the convection occurs is strongly modified by a decrease in the horizontal dissipation. The meanders develop earlier, their amplitude is larger, and the level achieved by $K_{e}$ is higher. Thus, horizontal mixing induced by the meanders is stronger than in experiment II and very deep convection is inhibited. Figure 20 shows the loss of potential energy due to the convective adjustment algorithm (CP) and $P \rightarrow K$ for experiments II, II-a, II-b, and II-c. The smaller the horizontal dis-

TABLE 2. Characteristics of the numerical experiments performed to study the model sensitivity to the horizontal dissipation.

\begin{tabular}{lccc}
\hline \hline & $\begin{array}{c}\text { Horizontal } \\
\text { resolution }\end{array}$ & $\begin{array}{c}\text { Dissipative } \\
\text { operator }\end{array}$ & $\begin{array}{c}\text { Horizontal } \\
\text { dissipative } \\
\text { coefficient }\end{array}$ \\
\hline $\begin{array}{c}\text { Basic case } \\
\text { (expt. II) }\end{array}$ & $4.5 \mathrm{~km}$ & $\begin{array}{c}\text { Second order } \\
\text { (Laplacian) }\end{array}$ & $80.0 \mathrm{~m}^{2} \mathrm{~s}^{-1}$ \\
$\begin{array}{l}\text { expt. II-a } \\
\text { expt. II-b }\end{array}$ & - & $\begin{array}{c}- \\
\text { Fourth order } \\
\text { (bi-Laplacian) }\end{array}$ & $\begin{array}{l}400.0 \mathrm{~m}^{2} \mathrm{~s}^{-1} \\
-2.10^{8} \mathrm{~m}^{4} \mathrm{~s}^{-1}\end{array}$ \\
expt. II-c & $2.0 \mathrm{~km}$ & $\begin{array}{c}\text { Second order } \\
\text { (Laplacian) }\end{array}$ & $20.0 \mathrm{~m}^{2} \mathrm{~s}^{-1}$ \\
\hline
\end{tabular}

sipation, the earlier and stronger the $P \rightarrow K$, and thus the weaker the CP and the smaller the depth of convection. This behavior confirms that in the model, meander development tends to restratify the surface layers of the neutrally stable area and thus limits the depth of convection.

\section{Discussion and conclusions}

Using a fine-scale version of the three-dimensional primitive-equation model of LODYC with a simple parameterization of convection, the oceanic response to thermohaline forcing has been investigated. The idealized thermohaline forcing we considered has successfully produced a deep convective region similar to that observed in winter in the NWM Sea. The preconditioning mechanism, whether it is due to topographic effects or to interaction between the local atmospheric forcing and the preexisting regional cyclonic circulation, or both, was roughly parameterized by the shape of the forcing. The preconditioning phase of DWF has not been investigated in this paper; only the violent mixing phase and ensuing sinking and spreading phase have been considered. Attention has been focused on the mesoscale features that developed during and after the forcing period, on their energetics, and on the regional circulation that was generated. The major conclusions are as follows (from small scale to regional scale).

The simple parameterization of convective motion that we use (i.e., a convective adjustment process plus vertical eddy viscosity and eddy diffusivity coefficients as a function of the local Richardson number) is able to produce a broad neutrally stable column of water of 1000-m thickness in the forcing area. The characteristics of the column are in good agreement with observations of MEDOC cruises. The existence of a subsurface source of heat and salt (LIW) significantly influences the $T-S$ characteristics of the deep water formed, but not the depth of convection. It only causes an extra 5-m deepening of the neutrally stable column due to cabbeling, which is negligible in comparison to the 1000-m depth of convection.

The formation of this column reveals an intrinsic limitation of a discretized representation of the ocean in a convective problem. We must choose a horizontal grid spacing, i.e., a scale under which phenomena must be parameterized by a dissipative operator. This scale is usually, for dynamical reasons, the first internal radius of deformation. But in our simulations, the radii of deformation continually diminish throughout the forcing period, since the thermohaline forcing tends to destroy the stratification. It is therefore impossible to always have a horizontal grid spacing less than the first radius of deformation, and we do not resolve smallscale energetic phenomena such as those described by Schott et al. (1988). Thus, the model dissipation 

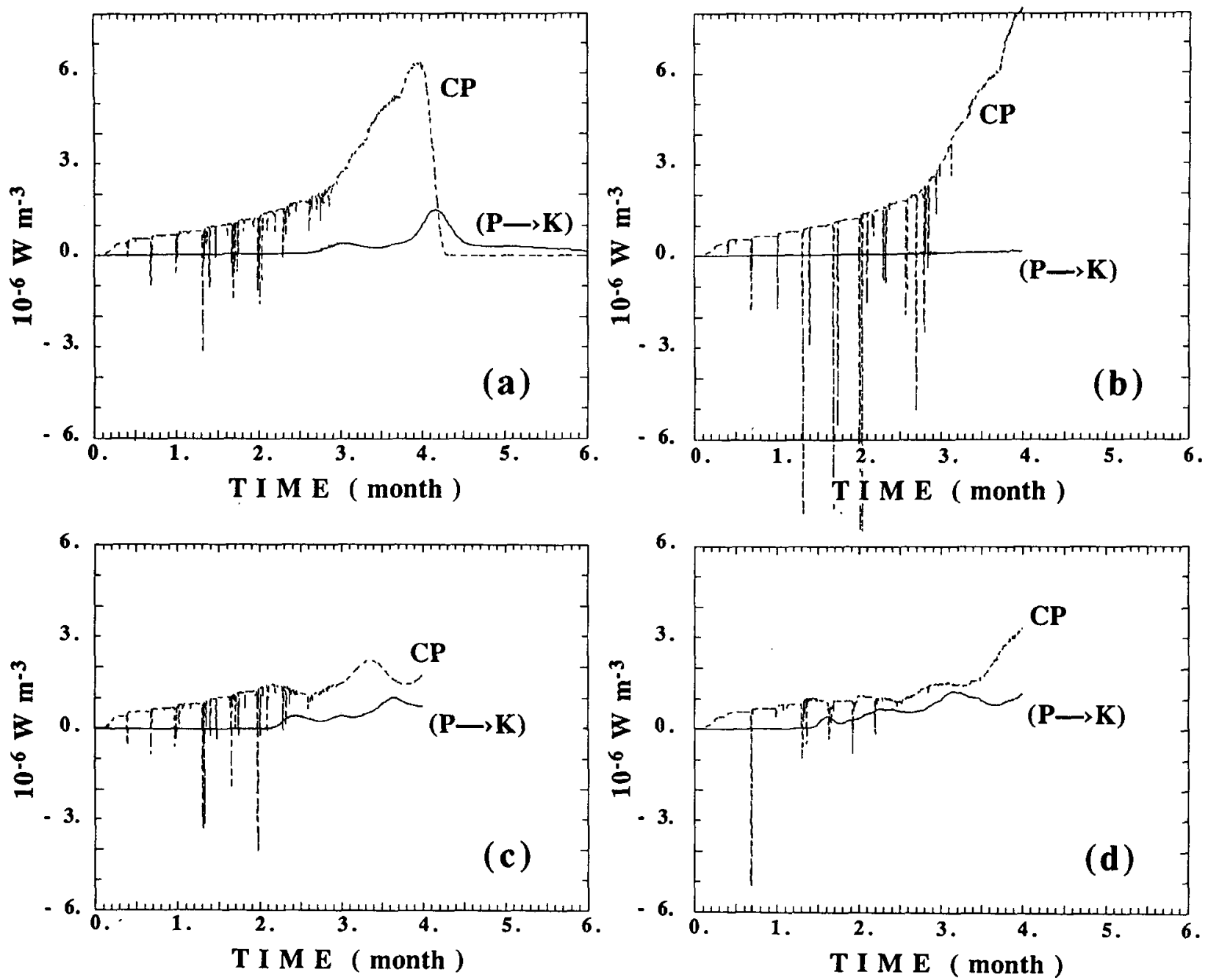

Fig. 20. Time evolution of the loss of potential energy (CP) induced by the convective adjustment process and the total conversion from $P$ to $K(P \rightarrow K):($ a) the basic case (experiment II); (b) the strongly dissipative case (experiment II-a); (c) the weakly dissipative case with a bi-Laplacian dissipative operator (experiment II-b); and (d) the high resolution $(2 \mathrm{~km}$ ) and weakly dissipative case (experiment II-c).

(which parameterizes subgrid-scale phenomena) is always strong, even with small eddy viscosity coefficients or with a higher order operator for the dissipation.

After 2 months of forcing, mesoscale meanders of 40-km wavelength develop around the neutrally stable column. Energy considerations show that the physical mechanism of meander amplification is a release of potential energy through baroclinic instability. The meanders generate pairs of small cells of strong upward and downward motion, which are associated with small eddies. The occurrence of these meanders and their associated structure are in good agreement with the observations of the violent mixing phase of DWF. In particular, the density maximum exhibits a phase lag between the surface and the bottom, and, similarly, phase lags appear between the extrema of temperature and salinity versus depth. These phase shifts are a con- sequence of the existence of the cells of intense vertical motion.

Meander development induces an advection of the lighter peripheral water into the surface layers of the neutrally stable column of water, while the more dense water in the column is advected toward the periphery. This results in modifications of the processes of convection. Within the column, the water mass formed is the result of the vertical mixing induced by static instability, which in turn is triggered by the thermohaline forcing. The advection of the lighter peripheral water into the surface layer of the column tends to diminish the occurrence of static instability, as well as resulting in the formation of lighter deep water. After a 3-month forcing period, a balance is reached between the horizontal density decrease induced by advection linked to meanders and the vertical density increase caused 
by the forcing. The neutrally stable column reaches a depth of $1400 \mathrm{~m}$ and no further changes in its depth occur until the development of $80-\mathrm{km}$ meanders near the end of the forcing period.

At the periphery, dense waters advected out of the neutrally stable column form the surface density crests of the meanders, which are associated with cyclonic perturbations of the surface current and cells of strong downward motion. The downward advection of water within these cells contributes to the violent mixing phase of DWF. The water mass formed is the result of both the surface convergence associated with the surface cyclonic perturbation and the surface density increase induced by the thermohaline forcing. But, because the forcing in our simulations is localized, the density crests of the meanders are less forced than the center water of the column. Thus, the water mass formed only reaches intermediate depths.

The two kinds of processes (convective and baroclinic adjustment) that have been advanced to explain the violent mixing phase of DWF occur in our simulations. They appear to be strongly linked: a baroclinic adjustment process can only occur at the edge of the column created through a convective process, whereas the depth to which convection can penetrate depends on the stratification, which in turn is affected by horizontal advection induced by the baroclinic adjustment process. In our simulations, the convective process appears to be the major component of DWF, but it seems difficult to extend this conclusion to the real ocean because of the spatial and temporal biases introduced by the thermohaline forcing we consider. The space variation of the forcing controls the horizontal density gradient, which drives the unstable density current and the baroclinic adjustment process, while the winter steady climatological heat and salt fluxes allows the formation of a balance between lateral advection of light peripheral water and the surface buoyancy input, a balance that inhibits the formation of very deep (dense) water. We anticipate that time variability of the forcing is of paramount importance. Large oceanic heat loss and evaporation occur over short intense periods (a few days), when wind events occur. During these periods, the convective process is augmented while meander growth is swamped by the surface buoyancy input (Killworth 1976); convection can penetrate down to the bottom. The effect of time and space variability of the thermohaline forcing on the processes of DWF is examined in a subsequent paper (Madec et al. 1990).

Toward the end of the forcing period, $80-\mathrm{km}$ meanders develop around the neutrally stable column. These meanders are also due to baroclinic instability. Eddies associated with these meanders are larger, as was observed in the MEDOC area during the sinking and spreading phase of DWF (Sankey 1973). The advection induced by these meanders is strong enough to erase the neutrally stable column even before the end of the forcing period. About two weeks after the end of the fourth month, both surface and subsurface waters have been restratified in the convective area. These results suggest that the column slumping, which has been observed during the final sinking and spreading phase of DWF, comes from the development of larger meanders toward the end of the winter period. These larger meanders are able to extract potential energy more efficiently through a baroclinic conversion.

The deep convective events strongly modify the circulation of the surrounding water. The regional circulation induced by DWF at first consists of a surface cyclonic circulation overlaying a weak anticyclonic circulation, in good agreement with the linear theory developed by Crépon et al. (1989). As meanders develop, a vertical mixing of momentum occurs that creates a cyclonic circulation throughout the water column at the periphery of the convective area. After six months, the northern coastal circulation is cyclonic from the surface to the bottom, except for a weak anticyclonic coastal countercurrent, which still persists. The total horizontal volumetric water mass transport of the coastal circulation reaches $2.2 \mathrm{~Sv}$ and is $1.2 \mathrm{~Sv}$ for the top $700 \mathrm{~m}$. Such values are of the order of magnitude of typical estimates of transport in the Mediterranean Sea. The latter value is nearly equal to the winter increase of the Liguro-Provencal Current transport as computed from observation (Béthoux et al. 1982). Nevertheless, the absolute value of the coastal current transport in the top $700 \mathrm{~m}$, which has been assumed to be about 2.2 Sv (Béthoux et al. 1982), is not well simulated, and the deep coastal current has not been observed so far by local measurements. Current meters moored recently along the French coast by Millot (personal communication 1989) indicate that the flow is westward throughout the water column. Moreover, observations (Béthoux et al. 1982; Astraldi et al. 1990) show that the maximum transport is found in early winter and not at the end of this season. In the present study, the maximum transport cannot be found at the beginning of the forcing period since we start from rest. The same discrepancy has been found with the quasi-geostrophic simulation performed by Barnier et al. (1989) in the state of statistical equilibrium (i.e., after 13 years of integration ). We infer that the winter increase of the transport of the LiguroProvencal current may be caused not only by a local effect, but also by a regional effect. This current could be sustained by the warm and fresh, and thus light, water that enters the NWM Sea along the west coast of Corsica and through the Corsica Channel.

The thermohaline forcing, induced by winter wind events, has clearly been shown to be a major component of the local dynamics in the northwestern Mediterranean Sea, although it is most likely not the only mechanism responsible for the Liguro-Provencal cir- 
culation. A companion paper (in preparation) will be devoted to the study of the combined effect of the local thermodynamic and dynamic forcing in this area.

Acknowledgments. This work is a contribution of EUROMODEL Program. We particularly thank B. L. Hua, F. Aikman, M. N. Houssais, and C. Millot for stimulating discussions. Funding has been provided by the EEC (European Economic Community) MAST 1 Program and the following French agencies: Direction des Recherches, Etudes et Techniques (DRET), and Centre National de la Recherche Scientifique (CNRS). Support for computations has been provided by the Conseil Scientifique de Centre de Calcul Vectoriel pour la Recherche (CCVR) and the Centre InterRegional de Calcul Electronic (CIRCE).

\section{APPENDIX}

\section{Potential Enstrophy Versus Energy Conserving Scheme}

The conversions from mean to eddy kinetic energy $\left(K_{m} \rightarrow K_{e}\right)$ and vice versa $\left(K_{e} \rightarrow K_{m}\right)$ are provided from the nonlinear terms of Eq. (1), multiplied by the mean current and by the departure from the mean current, respectively. $K_{m} \rightarrow K_{e}$ is the barotropic conversion-i.e., the conversion of mean to eddy kinetic energy through the Reynolds stress interacting with the shear of the mean flow. It is shown (Orlanski and Cox 1973 ) that $K_{e} \rightarrow K_{m}$ is equal in magnitude to $K_{m} \rightarrow$ $K_{e}$, but opposite in sign, if the total kinetic energy is

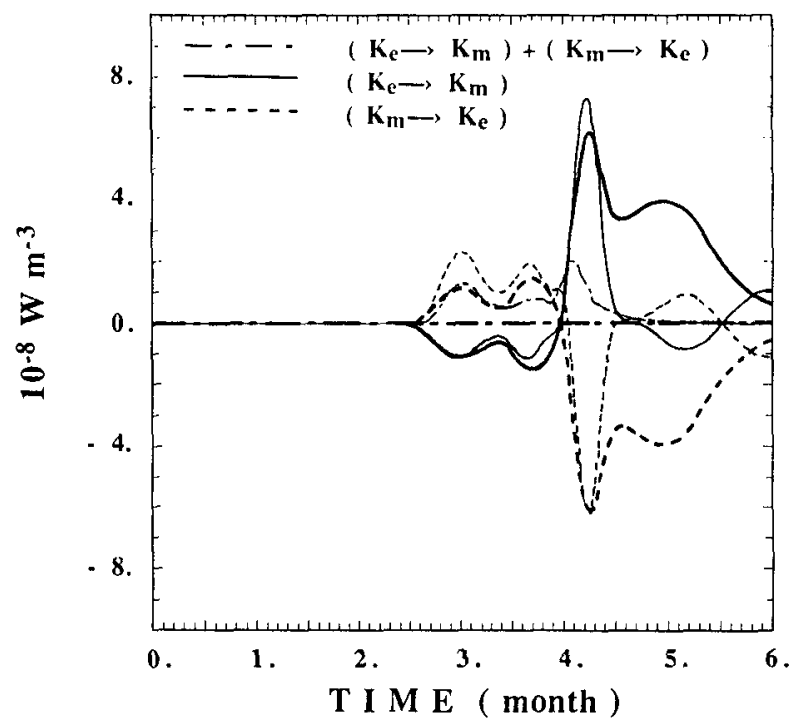

FIG. A1. Time evolution of the conversion terms between mean and eddy kinetic energy $\left(K_{m} \rightarrow K_{e}\right)$, and vice versa $\left(K_{e} \rightarrow K_{m}\right)$, for the potential enstrophy-conserving experiment (Experiment II) (fine curves) and the energy-conserving experiment (thick curves). The positive value of the sum $\left(K_{m} \rightarrow K_{e}\right)+\left(K_{e} \rightarrow K_{m}\right)$ for Experiment II reveals that $K_{m}$ is partly dissipated through the potential enstrophyconserving scheme we used for the nonlinear terms in this experiment.
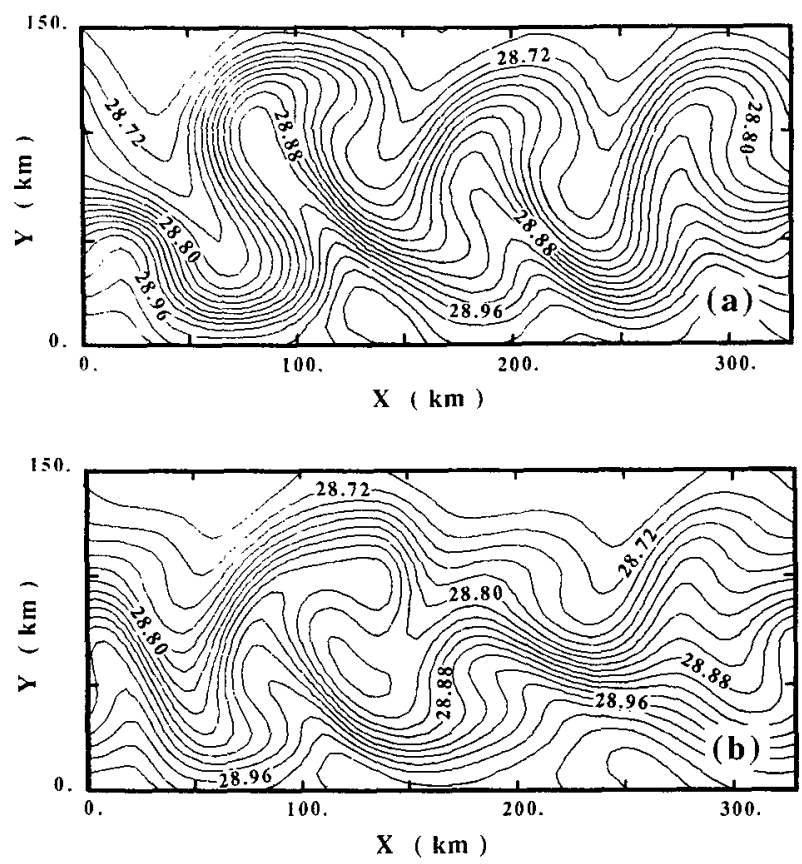

FIG. A2. Sea surface density ( $\sigma_{\theta}$ units) after 6 months: (a) potential enstrophy-conserving experiment (experiment II) and (b) energyconserving experiment. Contour interval equals $0.02 \mathrm{~kg} \mathrm{~m}^{-3}$.

conserved in the model basin. In the primitive equation model of LODYC, the nonlinear terms are approached by a potential enstrophy-conserving scheme that does not mathematically conserve energy, although energy is conserved to a good approximation in all our experiments.

In order to test the effect of this potential energyconserving scheme, a last experiment has been performed in the same configuration as experiment II, except that the potential enstrophy-conserving scheme has been replaced by an energy-conserving scheme. The time evolution of the different quantities of the energyflow diagram is similar for this experiment and experiment II, especially during the forcing period. The nature and the development of the meanders is not sensitive to the numerical scheme used. Figure A1 shows the time evolution of the conversion terms between mean and eddy kinetic energy for both experiments. The behavior is almost the same during the first four months. The loss of $K_{m}$ due to the potential enstrophyconserving scheme is weak and does not change significantly the energetics. The main difference between these two cases is in the long-term evolution of the oceanic response. The energy-conserving scheme induces an unrealistic cascade of enstrophy toward small scales, which keeps up the level of nonlinear exchanges of energy and generates higher dissipation of energy. This has been studied in detail by Sadourny (1975), who shows that "the compulsion to energy dissipation is a pathological feature of energy-conserving models." 
Moreover, the inverse cascade of energy toward the large scale degrades the results of the energy-conserving experiment. It significantly changes the structure of the density field (Fig. A2). The potential enstrophy-conserving model appears to be more suitable for our experiments. The long-term integration does not generate significant loss of energy at the explicit scales, and the model is computationally more stable than the energyconserving model (Sadourny 1975).

\section{REFERENCES}

Anati, D. A., 1971: On the mechanism of the deep mixed layer formation during MEDOC 69. Cah. Océanogr., 23, 427-443.

- and H. Stommel, 1970: The initial phase of deep water formation in the northwest Mediterranean, during MEDOC 69, on the basis of observations made by Atlantis II, January25February 12, 1969. Cah. Océanogr., 22, 343-351.

Andrich, P., 1988: A multitasked ocean general circulation model. Reference manual, LODYC, Université Paris 6, 60 pp.

__ G. Madec and D. L'Hostis, 1988: Performance evaluation for an ocean general circulation model: Vectorization and multitasking. Conf. Proc. of the Int. Conf. on Supercomputing, StMalo, France, AMC Press, 295-303.

Arakawa, A., 1972: Design of the UCLA general circulation model. Numerical Simulation of Weather and Climate, Dept. of Meteorology, University of California, Tech. Rep. 7, $116 \mathrm{pp}$.

Asselin, R., 1972: Frequency filter for time integrations. Mon. Wea. Rev., 100, 487-490.

Astraldi, M., G. P. Gasparini, G. M. R. Manzella and T. S. Hopkins, 1990: Temporal variability of currents in the eastern Ligurian Sea. J. Geophys. Res., 95(C2), 1515-1522.

Barnier, B., M. Crépon and C. Le Provost, 1989: Horizontal ocean circulation forced by deep water formation. Part II: A quasigeostrophic simulation. J. Phys. Oceanogr., 19, 1794-1808.

Batteen, M. L., and Y.J. Han, 1981: On the computational noise of finite-difference schemes used in ocean models. Tellus, 33, 387396.

Béthoux, J. P., L. Prieur and F. Nyffeler, 1982: The water circulation in the northwestern Mediterranean Sea, its relations with wind and atmospheric pressure. Hydrodynamics of Semi-Inclosed Seas, J. Nihoul, Ed., Elsevier, 129-142.

Boudra, D. B., R. Bleck and F. Schott, 1988: A numerical model of instabilities in the Florida Current. J. Mar. Res., 46, 715-791.

Bretherton, F. P., and M. Karweit, 1975: Mid-ocean mesoscale modeling. Numerical Models of Ocean Circulation, R. O. Reid, A. R. Robinson and K. Bryan, Eds., National Academy of Science, 237-249.

Bryan, K., 1969: A numerical method for the study of the circulation of the world ocean. J. Comput. Phys., 4, 347-379.

Bunker, A. F., 1972: Wintertime interactions of the atmosphere with the Mediterranean Sea. J. Phys. Oceanogr., 2, 225-238.

Carmack, E. C., and K. Aagaard, 1973: On the deep water of the Greenland Sea. Deep-Sea Res., 20, 687-715.

Chartier, M., 1985: Un modèle numérique tridimensionnel aux équations primitives de circulation générale de l'océan. Thèse de Doctorat, Université Paris 6, $111 \mathrm{pp}$.

Clarke, R. A., and J. C. Gascard, 1983: The formation of Labrador Sea Water. Part I: Large-scale processes. J. Phys. Oceanogr., 13, 1764-1778.

Crépon, M., and M. Boukthir, 1987: Effect of deep water formation on the circulation of the Ligurian Sea. Ann. Geophys., 5B(1), 43-48.

_- L. Wald and J. M. Monget, 1982: Low-frequency waves in the Ligurian Sea during December 1977. J. Teophys. Res., 87(C1), 595-600.
- M. Boukthir, B. Barnier and F. Aikman III, 1989: Horizontal ocean circulation forced by deep water formation. Part I: An analytical study. J. Phys. Oceanogr., 19, 1781-1792.

Csanady, G. T., 1982: Circulation in the Coastal Ocean. D. Reidel, $280 \mathrm{pp}$.

Eckart, C., 1958: Properties of water. Part II: The equation of state of water and sea water at low temperatures and pressures. $\mathrm{Am}$. $J$. Sci., 256, 225-240.

Gascard, J. C., 1973: Vertical motions in a region of deep water formation. Deep-Sea Res., 20, 1011-1027.

__, 1977: Quelques éléments de la dynamique de formation des eaux profondes méditeranéennes. Thèse de Doctorat d'Etat, Université Paris 6, France,

_- 1978: Mediterranean deep water formation, baroclinic instability and oceanic eddies. Oceanol. Acta, 1(3), 315-330.

- , and R. A. Clarke, 1983: The formation of Labrador sea water. Part II: Mesoscale and smaller-scale processes. J. Phys. Oceanogr., 13, 1779-1797.

Gordon, A. L., 1978: Deep Antarctic convection west of Maud Rise. J. Phys. Oceanogr., 8, 600-612.

Griffiths, R. W., and P. F. Linden, 1981: The stability of vortices in a rotating, stratified fluid. J. Fluid Mech., 105, 283-316.

Heburn, G. W., 1987: The dynamics of the Western Mediterranean Sea: A wind forced case study. Ann. Geophys., 5B(1), 61-74.

Hogg, N. G., 1973: The preconditioning phase of MEDOC 1969. Part II. Topographic effects. Deep-Sea Res., 20, 449-459.

Hsieh, W. W., M. K. Davey and R. C. Wajsowicz, 1983: The free kelvin wave in finite-difference numerical models. J. Phys. Oceanogr., 13, 1383-1397.

Jensen, T. G., 1986: Application of multi-level techniques to the Stommel problem with irregular boundaries. Advanced Physical Oceanographic Numerical Modelling. J. J. O'Brien, Ed., D. Reidel, 87-110.

Killworth, P. D., 1976: The mixing and spreading phases of MEDOC I. Progress in Oceanography, Vol. 7, Pergamon, 59-90.

- 1983: Deep convection in the world ocean, Rev. Geophys. Space Phys., 21 (1), 1-26.

Lacombe, H., 1974: Deep effects of energy transfers across the sea surface: The formation of deep waters. The Western Mediterranean, as an example. Presidential Address, Melbourne Int. Assoc. for Phys Sci of the Oceans, 52-85.

Loth, L., and M. Crépon, 1984: A quasi-geostrophic model of the circulation of the Mediterranean Sea. Remote Sensing of Shelf Sea Hydrodynamics, J. Nihoul, Ed., Elsevier, 277-285.

Madec, G., C. Rahier and M. Chartier, 1988: A comparison of twodimensional elliptic solvers for the barotropic streamfunction in a multilevel OGCM. Ocean Modelling, 78, 1-6. (Unpublished manuscript).

- M. Chartier and M. Crépon, 1991: Effect of thermohaline forcing variability on deep-water formation in the western Mediterranean sea: A high resolution 3D numerical study. Dyn. Atmos. Oceans, 15, 301-332.

Maillard, C., 1974: Formation d'eau profonde en mer Rouge. Processus de Formation des Eaux Océniques Profondes en Particulier en Méditerranée Occidentale, Centre National de la Recherche Scientifique, Paris, 115-125.

McDougall, T. J., 1983: Greenland Sea bottom water formation: A balance between advection and double-diffusion. Deep-Sea Res., 30, $1109-1117$.

MEDOC Group, 1970: Observation of formation of deep water in the Mediterranean Sea, 1969. Nature, 227, 1037-1040.

Millot, C., 1987: Circulation in the Western Mediterranean Sea. Oceanol. Acta, 10(2), 143-149.

shelf of the Gulf of Lions-observations and theory. J. Phys. Oceanogr., 11, 639-657.

Nielsen, J. H., 1912: Hydrography of the Mediterranean and adjacent waters. Report Dan. Oceanogr. Exp. 1908-1910, Rep. I, 72191. 
Orlanski, I., and M. Cox, 1973: Baroclinic instability in ocean currents. Geophys. Fluid Dyn., 4, 297-332.

Pacanowski, R. C., and S. G. H. Philander, 1981: Parameterization of vertical mixing in numerical models of tropical oceans. $J$. Phys. Oceanogr., 11, 1443-1451.

Pedlosky, J., 1987: Geophysical Fluid Dynamics. 2d ed. SpringerVerlag, $710 \mathrm{pp}$.

Sadourny, R., 1975: The dynamics of finite-difference models of the shallow-water equations. J. Atmos. Sci., 32, 680-689.

Saint-Guily, B., 1972: On the response of the ocean to impulse. Tellus, 24, 344-349.

Sankey, T., 1973: The formation of deep water in the northwestern Mediterranean. Progress in Oceanography, Vol. 6, Pergamon, 159-179.

Seung, Y. H., 1987: A buoyancy flux-driven cyclonic gyre in the Labrodor Sea. J. Phys. Oceanogr., 17, 134-146.

Schott, F., K. D. Leaman and R. G. Zika, 1988: Deep mixing in the Gulf of Lions, revisited. Geophys. Res. Lett., 15(8), 800-803.
Stommel, H., 1972: Deep winter-time convection in the Western Mediterranean Sea. Studies in Physical Oceanography: A Tribute to Georg Wüst on His 80th Birthday. Gordon and Breach, 207218.

Swallow, J. C., and G. F. Caston, 1973: The preconditioning phase of MEDOC 1969. Part I: Observations. Deep-Sea Res., 20, 429448.

Tang, C. M., 1975: Baroclinic instability of stratified shear flows in the ocean and atmosphere. J. Geophys. Res., 80(9), 1168-1175.

Tchernia, P., and M. Fieux, 1971: Résultats des observations hydrologiques exécutées à bord du N/O "Jean Charcot" pendant la campagne MEDOC 69 (30 janvier-28 février, 18-31 mars). Cah. Océanogr., 23, suppl. ${ }^{\circ} 1,1-91$.

Voorhis, A., and D. C. Webb, 1970: Large vertical currents observed in a western sinking region of the northwestern Mediterranean. Cah. Océanogr., 22, 571-580.

Wajsowicz, R. C., 1986: Free planetary waves in finite-difference numerical models. J. Phys. Oceanogr., 16, 773-789. 